OPEN ACCESS

Edited by:

Andres Alcover,

Institut Pasteur, France

Reviewed by:

Janis K. Burkhardt,

Children's Hospital of Philadelphia,

USA

Bernard Malissen

Centre d'Immunologie de Marseille

Luminy, France

${ }^{*}$ Correspondence:

Joanna Brzostek

micjmb@nus.edu.sg

Specialty section: This article was submitted to

$T$ Cell Biology,

a section of the journal

Frontiers in Immunology

Received: 0З November 2015

Accepted: 18 January 2016

Published: 04 February 2016

Citation:

Brzostek J, Gascoigne NRJ and

Rybakin V (2016) Cell Type-Specific Regulation of Immunological Synapse Dynamics by $B 7$ Ligand Recognition.

Front. Immunol. 7:24.

doi: 10.3389/fimmu.2016.00024

\section{Cell Type-Specific Regulation of Immunological Synapse Dynamics by B7 Ligand Recognition}

\author{
Joanna Brzostek ${ }^{1 *}$, Nicholas R. J. Gascoigne ${ }^{1}$ and Vasily Rybakin ${ }^{1,2}$ \\ ${ }^{1}$ Department of Microbiology and Immunology, Yong Loo Lin School of Medicine and Immunology Programme, National \\ University of Singapore, Singapore, Singapore, ${ }^{2}$ Laboratory of Immunobiology, Rega Institute for Medical Research, KU \\ Leuven, Leuven, Belgium
}

B7 proteins $\mathrm{CD} 80$ (B7-1) and CD86 (B7-2) are expressed on most antigen-presenting cells and provide critical co-stimulatory or inhibitory input to $\mathrm{T}$ cells via their T-cell-expressed receptors: CD28 and CTLA-4. CD28 is expressed on effector T cells and regulatory $T$ cells (Tregs), and CD28-dependent signals are required for optimum activation of effector T cell functions. CD28 ligation on effector T cells leads to formation of distinct molecular patterns and induction of cytoskeletal rearrangements at the immunological synapse (IS). CD28 plays a critical role in recruitment of protein kinase $C$ (PKC)- $\theta$ to the effector T cell IS. CTLA-4 is constitutively expressed on the surface of Tregs, but it is expressed on effector T cells only after activation. As CTLA-4 binds to B7 proteins with significantly higher affinity than CD28, B7 ligand recognition by cells expressing both receptors leads to displacement of CD28 and PKC- $\theta$ from the IS. In Tregs, B7 ligand recognition leads to recruitment of CTLA-4 and PKC- $\eta$ to the IS. CTLA-4 plays a role in regulation of T effector and Treg IS stability and cell motility. Due to their important roles in regulating T-cell-mediated responses, B7 receptors are emerging as important drug targets in oncology. In this review, we present an integrated summary of current knowledge about the role of B7 family receptor-ligand interactions in the regulation of spatial and temporal IS dynamics in effector and Tregs.

Keywords: Treg, PKC-theta, PKC-eta, CTLA-4, costimulation, immunological synapse, co-inhibition

\section{INTRODUCTION}

The adaptive immune system must distinguish between self and non-self in order to provide protection from pathogenic challenges while sparing the organism's own tissues. Recognition of B7 ligands (CD80 and CD86, also known as B7-1 and B7-2, respectively) by co-stimulatory CD28 and co-inhibitory CTLA-4 (cytotoxic T-lymphocyte-associated protein 4, also known as CD152) receptors plays a critical role in regulation of effective self versus non-self discrimination. CD28 signaling is required for optimum proliferation and function of effector T cells, whereas CTLA-4 plays a critical role in negative regulation of immune responses, as it is required for turning off effector $\mathrm{T}$ cell signaling and regulatory $\mathrm{T}$ cell (Treg) development and suppressive functions. These opposing immunomodulatory roles of CTLA-4 and CD28 are of considerable clinical significance. CTLA-4 was the first immune checkpoint receptor targeted for cancer immunotherapy, and the anti-CTLA-4 antibody ipilimumab is used in the clinic for treatment of advanced melanoma (1). 
CD28 co-stimulatory function is also relevant for cancer immunotherapy, as chimeric antigen receptors (CARs) containing CD28 cytoplasmic regions have been shown to induce efficient $\mathrm{T}$ cell effector functions (2). However, targeting CD28 with the superagonistic monoclonal antibody TGN1412 was a tragic failure, when administration of the antibody during a phase I clinical trial induced severe systemic inflammatory responses in healthy volunteers (3). Therefore, a comprehensive understanding of expression patterns, signaling pathways, and functional roles of CD28 and CTLA-4 on effector and Treg subsets can have significant medical impact.

CD28 and CTLA-4 recognize their B7 ligands in the context of the cell-to-cell interface, termed the immunological synapse (IS), formed between a $\mathrm{T}$ cell and an antigen-presenting cell (APC). Receptor ligation at the IS leads to accumulation of interacting molecules at different regions of the synapse, forming distinct molecular patterns known as supramolecular activation clusters (SMAC) (4-6). The canonical mature T cell IS consists of a central SMAC (cSMAC) containing TCR (on the T cell) and pMHC (on the APC) molecules, surrounded by the peripheral SMAC (pSMAC) containing LFA-1 (on T cell) and ICAM-1 (on APC) adhesion molecules as well as F-actin. The outer ring of the IS, known as the distal SMAC (dSMAC) contains molecules with large ectodomains, such as CD45 and CD43. The SMAC regions contain smaller microdomains, known as microclusters (7). The IS is highly dynamic, with movement of TCR microclusters toward the center of the synapse, where they undergo endocytosis. Antigen recognition under physiological conditions does not always result in formation of this canonical IS structure; nevertheless this model provides a useful framework for understanding spatial dynamics of molecular interactions at the interface between $\mathrm{T}$ cell and APC membranes. The IS is the main site of immune receptor triggering and recruitment of signaling intermediates, leading to signal initiation and integration. B7 ligand recognition leads to distinct localization of CD28 and CTLA-4 receptors at the SMAC, modulation of cytoskeletal dynamics as well as recruitment of protein kinase $\mathrm{C}$ (PKC) isoforms to the IS. The effect of B7 ligand recognition on the IS dynamics is cell type specific, with effector T cells and Tregs displaying different CD28 and CTLA-4 localization, leading to differential recruitment of PKC- $\theta$ and PKC- $\eta$ to the effector T cell and Treg synapses. This review presents a brief outline of the roles of CD28 and CTLA-4 in the immune system, followed by a more detailed discussion of CD28 and CTLA-4 localization patterns in the IS, and the consequences of B7 ligand recognition on IS structure and stability in T effector and Tregs.

\section{B7 LIGAND RECOGNITION: STRUCTURAL FEATURES AND EXPRESSION PATTERNS}

B7-1 and B7-2 (CD80 and CD86) molecules share a similar structure, consisting of one membrane-distal variable domain-like and one membrane-proximal constant domain-like immunoglobulin superfamily (IgSF) domain. Purified CD80 crystallizes in a dimeric form, and undergoes spontaneous homodimerization in solution (8), whereas CD86 crystalizes as a monomer (9). The two different oligomeric states of B7 were also observed using
Forster resonance energy transfer (FRET) analysis on the surface of APCs, with CD80 present on the cell surface mainly in the form of dimers, and CD86 being monomeric $(10,11)$. CD80 and CD86 are expressed on dendritic cells (DCs), macrophages, and $\mathrm{B}$ cells, with CD86 displaying higher constitutive expression and more rapid upregulation after activation. B7 molecules are also expressed on activated mouse and human effector T cells (12-14). CD80 and CD86 bind to CTLA-4 with significantly higher affinity than to CD28. CD80 is a stronger ligand, with $\mathrm{K}_{\mathrm{D}} 0.2 \mu \mathrm{M}$ for CTLA- 4 and $4 \mu \mathrm{M}$ for CD28 interaction, whereas the $\mathrm{K}_{\mathrm{D}}$ for CD86 binding to CTLA-4 is 2 and $20 \mu \mathrm{M}$ for CD28 (15).

CD28 monomers consist of a V-like IgSF extracellular domain, transmembrane regions, and a short cytoplasmic tail with no enzymatic activity. CD28 is expressed on the cell surface as a glycosylated, disulfide-linked homodimer of $44 \mathrm{kDa}$ chains. In adult humans, CD28 is constitutively expressed on approximately $80 \%$ of CD4+ and 50\% of CD8+ T lymphocytes. Loss of CD28 expression, most marked in the CD8 compartment, has been observed in humans during aging and autoimmune diseases (16-18). CD28 is expressed on all mouse T cells, and it is not downmodulated during aging (19). Repeated in vitro antigenic stimulation $(20,21)$ and exposure to common- $\gamma$ chain cytokines or type I interferons (22) leads to downregulation of CD28 expression on human T cells. However, in vivo antigenic stimulation has been reported to increase CD28 surface levels on mouse T cells (23).

CTLA-4 shares structural similarity with CD28, forming homodimers of V-like IgSF monomers. CTLA-4 contains a 36-amino-acid-long cytoplasmic tail with no enzymatic activity. CTLA-4 is not expressed on the surface of resting effector T cells $(24,25)$, but is expressed constitutively in Tregs (26) under control of Foxp3 and NFAT (27-29). In both conventional T cells and Tregs, surface CTLA-4 is continuously endocytosed via a clathrin- and dynamin-mediated pathway, and recycled to the plasma membrane (30-34). Activation of effector and Tregs leads to upregulated levels of CTLA- 4 on the cell surface. CTLA-4 internalization is mediated by the heterotrimeric adapter protein AP-2 $(30,34,35)$ [regulation of CTLA-4 trafficking is the subject of an excellent recent review in Ref. (36)], whereas CTLA-4 trafficking from the trans-Golgi network to the cell surface involves formation of a multimeric complex consisting of transmembrane adapters TRIM and LAX, as well as small GTPase Rab8 (37, 38). CTLA-4 present in recycling endosomes is protected from lysosomal targeting through interaction between LRBA protein (lipopolysaccharide-responsive and beige-like anchor protein) and CTLA-4's tail region (39). Since its lysosomal degradation involves interaction with another clathrin adaptor complex AP-1 that binds to the same tyrosine-based motif (Y201) of CTLA-4 as LRBA (35) (the interaction motifs in CTLA-4 cytoplasmic region are summarized in Figure 1), it has been suggested that the binding of LRBA may prevent interaction with AP-1 and thereby protect the protein from degradation (39).

Both CTLA-4 and CD28 rely on the amino acid motif MYPPPY in the vicinity of Y139 in human CTLA-4 and Y123 in CD28 for binding to the B7 proteins (46-48). Importantly, despite the identical amino acid sequence of the interaction site, CTLA-4 and CD28 are capable of effectively discriminating between B7 proteins. A key study from the Allison lab (48) reported that 


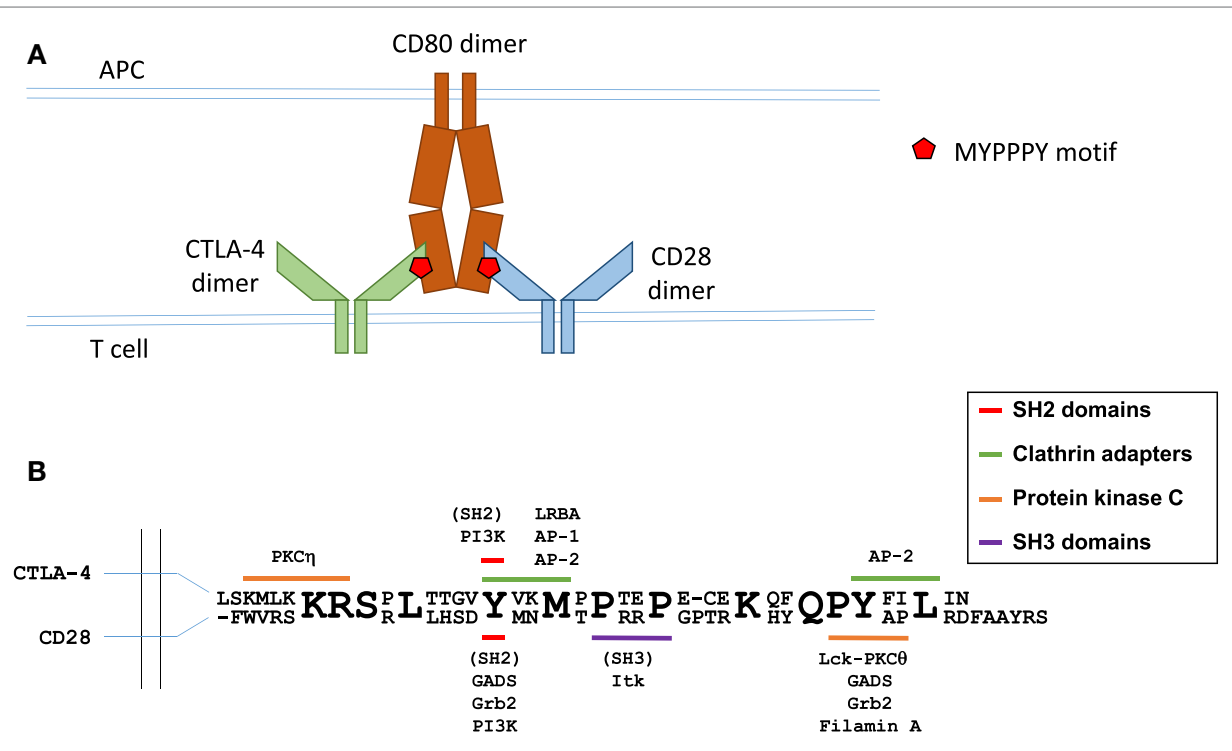

FIGURE 1 | Molecular interactions in B7 ligand recognition. (A) Schematic representation of CD28 and CTLA-4 binding to the B7 ligands. (B) Schematic representation of the cytoplasmic regions of CTLA-4 (top sequence) and CD28 (bottom sequence). Known interaction partners of CTLA-4 are shown above and of CD28 below the alignment, and the motifs implicated in these interactions are color coded as indicated. Figure based on Hou et al. (40), Isakov and Altman (41, 42), Margulies (43), Schneider and Rudd (36), Sharpe and Freeman (44), and Stamper et al. (45).

the binding of a B7 ligand was critical for the concentration of CTLA- 4 at the IS and contributed to the concentration of CD28, and that CD86 was a preferred ligand for CD28 and CD80 for CTLA-4. Antigen-pulsed B cells expressing CD80 effectively concentrated CTLA-4 at the synapse. Furthermore, in synapses formed by B cells expressing only CD80, there was evidence for competition between CTLA- 4 and CD28 for ligand binding, as CD28 accumulation was reduced even further when CTLA-4 was present at the IS. Conversely, peptide-pulsed B cells expressing only CD86 strongly increased the accumulation of CD28 at the synapse, but failed to recruit CTLA-4 (48).

\section{CD28 IN REGULATION OF THE IMMUNE RESPONSE}

CD28 is the prototypic co-stimulatory molecule, and CD28 ligation leads to enhanced cytokine production, cell survival, and proliferation of effector T cells. The critical role of CD28mediated signaling in optimum $\mathrm{T}$ cell responses is demonstrated by the $\mathrm{T}$ cell effector functions afforded to second-generation CARs containing cytoplasmic regions of $\mathrm{CD} 28$ and $\mathrm{CD} 3 \zeta$, but not by first-generation CARs lacking CD28 sequences (2). The cytoplasmic region of CD28 contains two main signaling motifs (summarized in Figure 1): a proximal YMNM motif and a distal proline-rich PYAP motif (49). The YMNM motif mediates phosphatidylinositol 3-kinase (PI3K) binding (50-52), leading to Akt activation; YMNM can also bind to GRB2/GADS adaptor proteins $(51,53)$ and the PYAP motif binds to Lck (54), filamin A, and GRB2/GADS $(53,55)$. The YMNM motif is followed immediately by another poly-proline motif PRRP, reported to bind the kinase Ikt (56). Analysis of knock-in mutant mice revealed that the PYAP motif is critical for IL-2 production and proliferation in vitro, as well as for in vivo antibody production and germinal center formation (57), whereas YMNM plays a role in augmenting $\mathrm{T}$ cell proliferation (58). Interestingly, knock-in T cells with both their YMNM and PYAP motifs mutated display less severe activation defects than CD28-deficient T cells, suggesting some functional role for the PRRP motif and/or yet unidentified cytoplasmic sequences.

CD28 is required for the thymic generation and peripheral maintenance of a functional Treg population. CD4+ Foxp3+ Tregs are key negative regulators of $\mathrm{T}$ cell-mediated immunity and are required for the control of spontaneous responses to self through several mechanisms $(59,60)$. Contact-mediated suppression relies on CTLA-4 interactions with its ligands and is discussed in detail below. Bystander suppression is mediated by suppressive cytokines, mainly IL-10 (61) and TGF- $\beta$ (62) produced by activated Tregs, and by induction of cytokine starvation in target cells by IL-2 clearance (63). B7 ligand recognition plays an important role in Treg development and function, summarized in Table 1. In CD28-deficient NOD mice, the percentage of peripheral Tregs is strongly reduced (64). Similar reductions are observed in NOD mice lacking both CD80 and CD86, leading to the conclusion that the B7-CD28 interaction is required for the formation of the full Treg repertoire. The reduction in the percentage of Tregs in NOD mice treated with B7-blocking CTLA-4-Ig correlates with a higher incidence of spontaneous autoimmune diabetes (64). Subsequent analysis revealed that Treg deficiency in $\mathrm{CD} 28^{-/-}$mice can be traced back to thymic development. The percentage of Treg precursors among thymic CD4 single-positive cells is significantly reduced in CD28 ${ }^{-/}$mice as well as in NOD mice injected with anti-CD80 and CD86 antibodies (65), and in B7 double knockout mice (66). 
TABLE 1 | B7 ligand recognition in Treg synapse formation and suppressive functions.

\begin{tabular}{|c|c|c|}
\hline $\begin{array}{l}\text { Surface } \\
\text { interactions }\end{array}$ & $\begin{array}{l}\text { Biological significance } \\
\text { for Tregs }\end{array}$ & Reference \\
\hline CD28-B7 & $\begin{array}{l}\text { Motility } \\
\text { Tonic signals necessary } \\
\text { for survival }\end{array}$ & $\begin{array}{l}\text { Lu et al. (160), Thauland } \\
\text { et al. (163) } \\
\text { Zhang et al. (71) }\end{array}$ \\
\hline CD28-B7 & $\begin{array}{l}\text { Antigen recognition } \\
\text { Motility stop signal }\end{array}$ & $\begin{array}{l}\text { Apostolou et al. (176), Jordan } \\
\text { et al. (68), Knoechel et al. (177), } \\
\text { Walker et al. (178) } \\
\text { Lu et al. (160), Thauland } \\
\text { et al. (163) }\end{array}$ \\
\hline \multirow[t]{2}{*}{ TCR-pMHC } & $\begin{array}{l}\text { Synapse formation and } \\
\text { stabilization }\end{array}$ & Onishi et al. (161) \\
\hline & Activation & $\begin{array}{l}\text { Schmidt et al. (179), Zhang } \\
\text { et al. (71) }\end{array}$ \\
\hline \multirow[t]{2}{*}{ LFA-1-ICAM-1 } & Proliferation & $\begin{array}{l}\text { Walker et al. (178), Zheng } \\
\text { et al. (155) }\end{array}$ \\
\hline & $\begin{array}{l}\text { Surface accumulation } \\
\text { of CTLA-4 }\end{array}$ & Catalfamo et al. (170) \\
\hline $\begin{array}{l}\text { CTLA-4-B7 } \\
\text { TCR-pMHC }\end{array}$ & Synapse stabilization & $\begin{array}{l}\text { Onishi et al. (161), } \\
\text { Zanin-Zhorov et al. (151) }\end{array}$ \\
\hline LFA-1-ICAM-1 & Contact suppression & $\begin{array}{l}\text { Kong et al. (152), Qureshi } \\
\text { et al. (146) }\end{array}$ \\
\hline
\end{tabular}

Peripheral homeostatic expansion of Tregs - but not effector T cells - in normal syngeneic hosts is also strongly suppressed by anti-CD80 and CD86 antibodies (66). A mechanistic explanation for the thymic requirement for CD28 was proposed by Tai et al. (67) who examined the consequences of CD28 deletion in a TCR-transgenic model. Mice expressing the AND TCR and its agonist ligand, a pigeon cytochrome $c$ peptide, were found to effectively induce thymic Tregs only in the presence of CD28. This means that while a strong selection signal through TCR is indeed required (68), it is not sufficient for the full initiation of the agonist selection program leading to the generation of Tregs, and that a co-stimulatory signal from mTEC-expressed B7 molecules through CD28 is also required. It is noteworthy that a small proportion of regulatory phenotype $\mathrm{T}$ cells were still generated in the absence of CD28 but these cells lacked suppressive capacity (67). Earlier data from the same group indicated that CD28 is also required for the deletion of thymocytes by negative selection $(69,70)$.

A study using mice in which CD28 was selectively deleted in cells expressing Foxp3 (Cd28- $\Delta$ Treg), reported only a minor decrease in the percentage of thymic Treg precursors (71). This is in line with previous observations that CD28 is involved in the generation of early, Foxp3-negative Treg precursors (72). However, in stark contrast to earlier studies, homeostatic expansion of Tregs in the periphery was reported to occur independently of CD28 (73). Tregs from CD28- $\Delta$ Treg mice displayed reduced suppressive capacity, and consequently CD28- $\Delta$ Treg animals developed spontaneous autoimmunity (71). Costimulation through CD28 is required for in vivo expansion of Tregs in the presence of TCR stimulation and IL-2 (74). CD28 stimulation is also required for the conversion of naïve CD4 T cells into Tregs in vivo $(75,76)$ and in vitro (77).

\section{CTLA-4 IN REGULATION OF THE IMMUNE RESPONSE}

CTLA-4 is a critical negative regulator of the immune response. Germline CTLA-4 knockout in mice results in massive lymphoproliferation $(78)$, and is lethal at $3-4$ weeks of age $(78,79)$. The peripheral $\mathrm{T}$ cell profile in these animals is strongly skewed toward CD4 cells that rapidly proliferate in a CTLA-4-Ig-sensitive manner - indicating the dependence on B7-CD28 interaction - and infiltrate non-lymphoid tissues $(78,80)$. Introduction of CTLA-4-sufficient Tregs reverts the lymphoproliferative disorder and prevents early lethality in CTLA-4 knockout mice (81), whereas blocking of CTLA-4 on Tregs completely abrogates their suppressive function $(62,66,82)$. CTLA-4-deficient Tregs are unable to control lymphopenia-driven homeostatic expansion of conventional CD4 cells (83). Importantly, interaction between CTLA-4 and B7 expressed on effector T cells was found to be dispensable for the control of the latter in mixed bone marrow chimera experiments as both $\mathrm{B} 7^{-1-} \mathrm{CTLA}-4^{-/-}$and B $7^{+/+}$CTLA- $4^{-/-}$effector $\mathrm{T}$ cells were efficiently suppressed by CTLA-4-sufficient Tregs (66). B7 expression is also not required on Tregs themselves (66). These data indicate that B7 expressed on a cell subset distinct from effector and Tregs mediates interactions with Treg-expressed CTLA-4 and immune suppression. CTLA-4-deficient Tregs are characterized by similar expression of CD25, PD1, GITR, and of suppressive cytokines IL-10 and IL-35 (83). Foxp3 promoter-controlled deletion of CTLA-4 in Tregs resulted in lymphoproliferative disease and tissue infiltration, and was lethal at $\sim 7-8$ weeks of age [i.e., somewhat delayed compared to germline knockout Ref. (84)]. Similarly to Foxp3-driven CD28 deficiency, thymic development of Tregs was normal, as was their survival in the periphery. However, cells lacking CTLA-4 were unable to control proliferation of target cells stimulated by antiCD3 antibody and DC, and to induce tumor rejection (84).

Unlike CD28, CTLA-4 is not required for Treg development in the thymus. CTLA- 4 is expressed by a subset of thymocytes predominantly residing at the corticomedullary junction (85) and is strongly upregulated upon induction of negative selection (86). There is no requirement for CTLA-4 expression to initiate central Treg development and peripheral expansion, as CTLA-4 knockout mice exhibit elevated percentage of Tregs and increased Ki67 expression, indicative of their active proliferation (87). Moreover, deletion of CTLA-4 in TCR-transgenic mice increases the frequency of Foxp3-positive Treg precursors in the thymus and leads to the formation of a specific population of Foxp3-positive DP thymocyte subsets in the thymic cortex (85). However, CTLA-4 can play a role in formation of the induced Treg population, as CTLA- 4 has been shown to induce expression of Foxp3 and Treg conversion in the intestine (88).

\section{CD28 AND IMMUNOLOGICAL SYNAPSE ARCHITECTURE IN EFFECTOR T CELLS}

CD28 shows a unique cSMAC localization pattern that is important for its efficient co-stimulatory functions. CD28 co-localizes with TCR microclusters at the earliest observable time-point after 
agonist pMHC recognition $(89,90)$, and the early accumulation of CD28 at the IS shows similar kinetics and localization as the TCR complex. In a mature IS, CD28 is present at the cSMAC, but segregates away from TCR $(90,91)$. This segregation of CD28 from TCR at the IS is required for optimum T cell activation, as shown in a study comparing different anti-CD3 and CD28 micropatterns on planar stimulatory surfaces (92). The spatial separation of TCR and CD28 at the mature IS is regulated by localization of CD28 ligands, as full length CD80 separates from TCR at the IS, but CD80 with deleted cytoplasmic region localizes with TCR (93). Moreover, the tailless CD80 molecule does not provide an optimum co-stimulatory signal and does not show efficient accumulation at APC: T cell contact interface $(94,95)$. This suggests a role for B7 interactions with cytoskeleton and/or other cytoplasmic components in regulation of IS architecture. CD28 recruitment and maintenance at the synapse requires both CD28 and TCR ligand binding $(90,96)$. CD28 accumulation at the synapse has been shown to be independent of antigenic pMHC affinity to TCR, with weak and strong agonist pMHC complexes inducing similar levels of CD28 recruitment (97). The role of CD28-mediated signaling and interactions in regulation of CD28 localization at the synapse is somewhat controversial, with a report indicating unperturbed IS localization of CD28 with mutated or deleted cytoplasmic region (90), whereas another study observed impaired IS localization of CD28 with deleted cytoplasmic domain or with a mutation at Y188 within the CD28 PYAP motif (96).

CD28 ligation has been shown to induce rapid internalization of the receptor, with half of the endocytosed fraction degraded in lysosomes and half recycled back to the cell surface (98). CD28 downregulation depends on PI3K (73), with preferential endocytosis of CD28 molecules associated with PI3K (98). CD28 is endocytosed via clathrin-coated pits, and this process requires coupling of WASP to PI3K and CD28 via sorting nexin 9 (73). CD28 downregulation from the synapse can also be influenced by stoichiometry of its B7 ligands (11). FRET analysis of B7 fluorescent protein fusions demonstrated that CD80 is present at the cell surface as a mixed population of dimers and monomers, with CD86 predominantly present in monomeric form (10). Experimental increase in CD80 dimerization resulted in enhanced T cell: APC conjugate formation and more sustained accumulation of Lck and PKC- $\theta$ at the IS (11).

Co-stimulatory signals play a critical role in regulation of cytoskeleton dynamics at the IS during $\mathrm{T}$ cell interaction with APC (summarized in Table 2). CD28 ligation induces movement of actin cytoskeleton toward the IS (99), and CD28 engagement is required for sustained actin accumulation at the IS (100). CD28 stimulation alone leads to actin polymerization and recruitment of actin at the IS (101). CD28 signaling is important in multiple pathways involved in actin filament nucleation, elongation, and depolymerization. The guanine nucleotide exchange factor Vav1 controls the activity of small Rho GTPases Cdc42 and Rac1 that regulate actin polymerization activity of WASP and WAVE2, respectively. WASP and WAVE2 are actin nucleation-promoting factors that, together with the Arp2/3 complex, facilitate formation of new actin filaments.

CD28 ligation induces tyrosine phosphorylation of Vav1 (102), and CD28-dependent actin remodeling requires Cdc42 (103) and Rac1 (104). The molecular interactions linking CD28 to Vav1 phosphorylation are not yet fully elucidated. CD28-dependent Vav1 phosphorylation has been shown to require binding of the adaptor protein GRB2 to CD28 $(105,106)$, but a recent report provided evidence for GRB2-independent Vav1 binding to CD28 and a role of PIP5K1A (phosphatidylinositol 4-Phosphate 5 -Kinase $\alpha$ ) and Vav1 cooperation in regulation of actin, downstream of CD28 (107). Jurkat cells expressing CD28 with mutated C-terminal PYAP motif, important for GRB2 binding, failed to recruit Vav1 to the IS or to rearrange actin after CD28 ligation (107); however, Vav1 phosphorylation in response to CD28 ligation was not assessed in this study, and in another report the PYAP motif was shown to be dispensable for CD28-dependent Vav1 phosphorylation (108). The Arp2/3 actin nucleation complex cooperates with filamins, large multidomain proteins with a role in actin crosslinking (109), to establish actin structure. Filamin A is phosphorylated (110) and recruited to the IS (108) after CD28 ligation in T cells, with the PYAP motif on the cytoplasmic region of CD28 mediating the interaction with filamin A (108, 111). Knockdown of filamin A expression did not affect CD28mediated Vav1 phosphorylation, but reduced Cdc42 activity and impaired CD28-mediated costimulation (108). However, changes

TABLE 2 | CD28 in regulation of cytoskeleton dynamics at the immunological synapse.

\begin{tabular}{|c|c|c|c|}
\hline Cytoskeletal regulator & CD28-induced modification & Effect on cytoskeleton & Reference \\
\hline Vav1 & Phosphorylation, leading to activation & $\begin{array}{l}\text { Vav1 controls activity of small Rho GTPases Cdc42 } \\
\text { and Rac1 that regulate actin polymerization activity } \\
\text { of WASP and WAVE2, respectively }\end{array}$ & $\begin{array}{l}\text { Nunes et al. (102), Raab et al. } \\
\text { (104), Salazar-Fontana et al. (103), } \\
\text { Schneider and Rudd (106) }\end{array}$ \\
\hline Filamin A & $\begin{array}{l}\text { Direct interaction with CD28, } \\
\text { phosphorylation }\end{array}$ & Filamin A has a role in actin crosslinking & $\begin{array}{l}\text { Muscolini et al. (111), Tavano et al. } \\
\text { (108) }\end{array}$ \\
\hline Cofilin & Dephosphorylation, leading to activation & $\begin{array}{l}\text { Actin severing protein. Blocking cofilin-actin } \\
\text { interaction reduces T cell:APC conjugation }\end{array}$ & $\begin{array}{l}\text { Lee et al. (119), Wabnitz et al. } \\
\text { (120) }\end{array}$ \\
\hline
\end{tabular}

Rltpr Unknown

Actin-uncapping protein. Wild-type Rltpr is required Liang et al. (113) for CD28-dependent costimulation, but this seems to be independent of its actin-uncapping function

CapZIP Phosphorylation Actin-uncapping protein. CapZIP is required for Tian et al. (110) CD28-dependent costimulation, but its effect on $T$ cell cytoskeleton are unknown 
in actin structure or dynamics at the IS of filamin A knockdown cells have not been reported. Moreover, knocking down filamin A did not impair ezrin accumulation at the IS (108).

Actin filaments contain a fast growing barbed end, which can be bound to actin capping protein. Capping protein binding to the barbed end prevents addition of new actin subunits, limiting the filament elongation. Actin capping and subsequent actin polymerization can be regulated by actin-uncapping proteins (112). An actin-uncapping protein Rltpr is required for CD28dependent costimulation (113), and Rltpr colocalizes with CD28 in CD80-dependent signaling microclusters (113), suggesting a role of Rltpr in CD28-mediated actin rearrangement at the synapse. However, a direct role of Rltpr for CD28-dependent actin modification is unclear. Rltpr does not immunoprecipitate with CD28 (113) and is not phosphorylated after CD28 ligation (110). Moreover, an Rltpr mutation that abolishes CD28-mediated costimulation does not impair Rltpr's actin-uncapping ability or CD28-dependent actin rearrangements at the synapse (113). The Rltpr mutation that reduced CD28-dependent costimulation abrogates CD28-dependent recruitment of PKC- $\theta$ and Carma1 to the IS (113) through a yet unidentified molecular mechanism, suggesting that Rltpr acts as an adaptor at the IS independently of its actin-uncapping functions. A recent phosphoproteomic screen identified actin-uncapping CapZIP as part CD28 signaling network (110). Importantly, CapZIP is required for CD28dependent costimulation of cytokine production (110). However, it has not yet been reported if CapZIP can directly interact with CD28 and if it is required for CD28-dependent changes in actin dynamics. In summary, the current evidence suggests that CD28-dependent signaling may regulate actin capping through actin-uncapping proteins CapZIP and potentially Rltpr.

CD28 signaling regulates actin dynamics through control of activity of the actin-severing protein cofilin. Cofilin is a ubiquitously expressed $19 \mathrm{kDa}$ protein that cleaves actin filaments, thus, promoting actin depolymerization, but also creating new barbed ends for filament elongation (114). Cofilin's actin binding capacity is negatively regulated by its phosphorylation at serine 3 $(115,116)$, and binding to phospholipids (117). Blocking cofilin interaction with actin reduces $\mathrm{T}$ cell proliferation and cytokine production, as well as conjugation with APCs (118). In resting human T cells, cofilin is present mainly in the inactive phosphorylated form, and CD28 or CD2 signal together with TCR, but not TCR signal alone, induces cofilin dephosphorylation and actin binding $(119,120)$. The precise sequence of signaling events linking CD28 ligation to cofilin activation is unknown. Cofilin is dephosphorylated by serine phosphatases PP1 and PP2A (121), and CD3/CD28-induced cofilin dephosphorylation requires Ras (120). Additionally, CD28 may regulate cofilin activity through control of levels of membrane phospholipids (114).

There is strong evidence that CD28-dependent regulation of actin dynamics is important for the effector $\mathrm{T}$ cell functions. CD28 enhances T cell:APC conjugate formation in vitro (122, 123). Knock-in mice with mutated PYAP motif show reduced IL-2 production and proliferation in vitro, and impaired in vivo antibody production and germinal center formation (57). This could be a result of impaired cytoskeletal rearrangement, as the PYAP motif is implicated in Vav1 and filamin A recruitment. However, the effects of PYAP mutations on cytoskeletal dynamics and synapse stability have not yet been reported for primary $\mathrm{T}$ cells, and this motif is also important for binding to Lck (54), GRB2/GADS (53, 55), and PKC- $\theta$ (124), as discussed below. Analysis of a mouse mutant with inducible inhibition of Csk, a negative regulator of Src family kinases, strongly suggested that CD28-dependent actin remodeling is critical for initiation of full TCR signal in thymocytes (125). However, thymocytes from PYAP mutant knock-in mice do not show obvious phenotypic defects (57), suggesting that CD28-independent pathways can regulate actin cytoskeleton dynamics during thymocyte development.

\section{CD28 AND REGULATION OF PKC- $\theta$ LOCALIZATION AT THE EFFECTOR T CELL IS}

$\mathrm{CD} 28$ plays a critical role in regulation of the IS localization of the novel protein kinase $\mathrm{C}$ (nPKC) isoform PKC- $\theta$ (summarized in Table 3). The PKC family consists of 10 serine/threonine kinase isoforms, with important roles in regulation of multiple cellular processes in different cell types. All nPKC isoforms (PKC- $\theta$, PKC- $\delta$, PKC- $\epsilon$, and PKC- $\eta$ ) require diacylglycerol (DAG), but

TABLE 3 | Molecular determinants of PKC- $\theta$ localization at the immunological synapse.

\begin{tabular}{ll}
\hline Interaction/activity & Molecular determinants \\
\hline PKC- $\theta-C D 28$ & $\begin{array}{l}\text { Polyproline motif within the PKC- } \theta \text { V3 hinge region } \\
\text { and PYAP motif in CD28; Lck-mediated interaction }\end{array}$
\end{tabular}

PKC- $\theta-C D 28$ Sumoylation of PKC- $\theta$ at lysines 325 and 506

PKC- $\theta-D A G$

C1 domains of PKC- $\theta$

PKC- $\theta$ kinase

activity

Ritpr
Unknown, possibly through autophosphorylation at threonine 219 between the tandem C1 domains

Unknown, no interaction between RItpr and PKC- $\theta$ has been detected

\section{Effect on immunological synapse}

PKC- $\theta$ V3 hinge and CD28 PYAP motif are required for CD28 cSMAC localization

Abrogated PKC- $\theta$ sumoylation reduces PKC- $\theta$ localization at the IS and its colocalization with CD28, induces colocalization of PKC- $\theta$ and filamin A at periphery of the IS

C1 domains mediate initial PKC- $\theta$ recruitment to the synaptic membrane, but they do not support PKC- $\theta$ central accumulation at the synapse

PKC- $\theta$ kinase activity is required for its recruitment to the IS

Wild-type Ritpr is required for PKC- $\theta$ and CARMA1 recruitment to cSMAC

\section{Reference}

Kong et al. (124)

Wang et al. (139)

Basu et al. (134), Carrasco and Merida (136), Quann et al. (135)

Cartwright et al. (138),

Thuille et al. (137)

Liang et al. (113) 
not $\mathrm{Ca}^{2+}$, for activation, and are expressed in $\mathrm{T}$ cells and play multiple roles in regulation of $\mathrm{T}$ cell signaling and effector functions (126). Central localization of PKC- $\theta$ is one of the hallmarks of the mature effector T cell IS. A seminal study by Monks at al. identified PKC- $\theta$ as the only PKC isoform recruited to effector $\mathrm{T}$ cell IS (127). However, more recent studies show that PKC- $\eta$ and PKC- $\epsilon$ are also recruited (128-130), with some evidence that their recruitment precedes that of PKC- $\theta$ (129). PKC- $\epsilon$ and PKC- $\eta$ display homogeneous distribution over the entire synapse, whereas PKC- $\theta$ displays discrete $\mathrm{CSMAC}$ localization contained within the peripheral actin ring (128-132).

An important study using lipid bilayers presenting antigen and co-stimulatory signal, and TIRF microscopy to examine PKC- $\theta$ localization at the effector T cell IS, revealed initial colocalization of PKC- $\theta$ with TCR/CD28 microclusters (90). This was followed by $\mathrm{PKC}-\theta$ recruitment to the CSMAC, where it segregated, together with $\mathrm{CD} 28$, to $\mathrm{TCR}^{\text {low }}$ regions in the periphery of cSMAC (90). The initial stages of PKC- $\theta$ recruitment to the effector T cell IS do not depend on CD28 ligand binding, but CD28 ligation is required for sustained PKC- $\theta$ localization at the synapse and colocalization of PKC- $\theta$ with CD28 $(90,133)$. PKC- $\theta$ interacts with CD28 after PMA treatment (90) (which induces PKC activation) and TCR/CD28 stimulation (124).

The molecular determinants of PKC- $\theta$ synapse localization have been mapped to the V3 hinge region and C1 domains (132). nPKCs share a conserved structure, with an amino-terminal C2 domain, tandem C1 domains, and V3 hinge linked to a carboxyl-terminal kinase domain. PKC- $\theta$ interaction with CD28 and $\mathrm{CSMAC}$ localization requires a polyproline motif within the V3 hinge region (124), and V3 hinge regions from PKC- $\epsilon$ and PKC- $\eta$ mediate their diffuse accumulation at the synapse (134). A carboxyl-terminal poly-proline motif (PYAP) in the CD28 cytoplasmic tail is required for its interaction with PKC- $\theta$, with strong evidence suggesting that this is an indirect interaction mediated through Lck, with the Lck SH3 domain binding to the polyproline motif in PKC- $\theta \mathrm{V} 3$ and the Lck SH 2 domain binding a phosphorylated tyrosine within the CD28 PYAP motif (124). Tyrosine 188 within the PYAP motif was also identified as critical for CD28 and PKC- $\theta$ central synapse localization in an earlier study (96).

Additionally, C1 domains of PKC- $\theta$ also play a role in its synapse localization, through interaction with DAG at the synapse membrane $(134,135)$. C1 domains can mediate initial PKC- $\theta$ recruitment to the synaptic membrane (135), but they do not support PKC- $\theta$ central accumulation and retention and the membrane (136), and $\mathrm{nPKC} \mathrm{C1}$ domains are not sufficient to determine the respective synapse localizations of PKC- $\theta$ versus PKC- $\epsilon$ and PKC- $\eta$ (134). Phosphorylation of PKC- $\theta$ threonine 219 (T219), in a hinge region between the tandem C1 domains, is required for PKC- $\theta$ localization at the IS (137). Moreover, sustained synapse localization is dependent on PKC$\theta$ kinase activity $(137,138)$, most likely through a requirement for PKC- $\theta$ autophosphorylation at T219 (132, 137). PKC- $\theta$ recruitment to the IS also requires expression of wild-type Rltpr actin-uncapping protein (113). T cells from mice expressing an Rltpr mutant could not recruit PKC- $\theta$ to the IS (113). The precise role of Rltpr in the regulation of PKC- $\theta$ synapse localization is unknown but seems to be independent of Rltpr actin-uncapping function, and no direct interactions between Rltpr and PKC- $\theta$ have been observed (113).

A recent report identified a novel activation-dependent posttranslational modification of PKC- $\theta$ that modulates CD28-PKC$\theta$ interactions and IS architecture (139). TCR stimulation of resting murine and human T cells leads to conjugation of SUMO1 (small ubiquitin-like modifier) to PKC- $\theta$ lysine (K) 325 and K506 by SUMO E3 ligase PIASx $\beta$ (139). Importantly, TCR and CD28 costimulation resulted in stronger PKC- $\theta$ sumoylation than TCR stimulation alone. Sumoylation-resistant PKC- $\theta$ with mutated K325 and K506 residues showed reduced interaction with CD28 and filamin A, and diffuse localization at the membrane in the IS (139). Inhibiting PKC- $\theta$ sumoylation through PIASx $\beta$ knockdown or overexpression of a desumoylating enzyme also abrogated PKC- $\theta$ localization at the IS, and reduced its colocalization with CD28 (139). Wild-type PKC- $\theta$ segregated from filamin A at the IS, with mainly pSMAC localization of filamin A. Inhibition of PKC- $\theta$ sumoylation altered the IS architecture, inducing colocalization of PKC- $\theta$ and filamin A at the periphery of the synapse (139).

The localization of PKC- $\theta$ to the center of the IS is critical for its functions in effector $\mathrm{T}$ cells. Mutations of the poly-proline motif in the $\mathrm{V} 3$ region of $\mathrm{PKC}-\theta$ reduced activation of primary effector CD4+ T cells (124). Critically, overexpression of murine V3 domain sequesters PKC- $\theta$ from CD28 and cSMAC in mouse $\mathrm{CD} 4+\mathrm{T}$ cells, and reduces $\mathrm{PKC}-\theta$-dependent gene expression in vitro, as well as CD4+ Th2 and Th17 immune responses in vivo (124). Similarly, expression of sumoylation-resistant PKC- $\theta$ mutants, with impaired synapse localization, does not rescue defects in cytokine production, activation of PKC- $\theta$ dependent transcription factors, and Th2 differentiation of human $\mathrm{T}$ cells with downregulated expression levels of endogenous PKC- $\theta$ (139). Additionally, mutations in the CD28 PYAP motif, required for PKC- $\theta$ interaction with CD28 and for IS localization, severely impaired effector $\mathrm{T}$ cell functions in vivo (57). However, it must be noted that PKC- $\theta$ synapse localization seems to be inseparable from its interaction with $\mathrm{CD} 28$, and the observed functional effects of impaired PKC- $\theta$ synapse recruitment could also be caused by reduced CD28 interactions with PKC- $\theta$, Lck, and/or filamin A.

\section{CTLA-4 DYNAMICS AT THE EFFECTOR AND Treg IS}

Recognition of B7 ligands by CD28 and CTLA-4 at the effector $\mathrm{T}$ cell IS leads to competitive displacement of CD28 and PKC- $\theta$ from its central region. In the absence of stimulation, regulatory and conventional $\mathrm{T}$ cells express similar levels of CD28, but CTLA-4 expression is significantly higher in unstimulated Tregs $(71,140,141)$. TCR signaling induces polarization of both intracellular (142) and membrane pools of CTLA-4 toward the IS of effector T cells, and TCR signal strength determines CTLA-4 localization at the IS (97). CTLA-4 is recruited to the effector $\mathrm{T}$ cell cSMAC with delayed kinetics relative to that of TCR and $\mathrm{CD} 28$, segregates away from $\mathrm{CD} 3^{\text {high }}$ regions and forms a ring-like 
structure (141). CTLA-4 recruitment to and stabilization at the IS depends on its ligand binding, but occurs at both high and low B7 ligand densities (141). Critically, recruitment of CTLA-4 to the IS influences CD28 localization, due to competition for ligand binding. At high ligand densities, CTLA-4 recruitment leads to exclusion of CD28 from the cSMAC and its accumulation outside the pSMAC (141). At low ligand densities, CTLA-4 prevents formation of CD28 clusters at the T effector IS (141). Importantly, CTLA-4-mediated displacement of CD28 from the cSMAC leads to impaired synaptic localization of PKC- $\theta$ (141). CTLA-4 ligation has also been reported to reduce the size of $\mathrm{T}$ cell: APC contact interface and to reduce ZAP70 microcluster formation (143).

The localization of CTLA- 4 in the T effector synapse depends on the molecular dimensions of the extracellular region of the protein, as CTLA- 4 molecules with elongated ectodomains failed to accumulate at CSMAC despite unimpaired ligand binding (141). However, it has not been reported if CTLA-4 with elongated ectodomains affected CD28 clustering at the synapse, and it is not known whether similar dimensions of CD28 and CTLA-4 receptor-ligand complexes are important for efficient regulation of co-stimulatory signal and/or competition for ligand binding at the synapse. The matching sizes of activating and inhibitory receptor-ligand complexes are critical for signal integration and regulation of NK-cell functions $(144,145)$, and it is plausible that a similar requirement exists for co-stimulatory and co-inhibitory signaling in effector $\mathrm{T}$ cells.

A molecular mechanism for CTLA-4 involvement in the downregulation of CD80/CD86 has been established in the seminal work by Qureshi et al. (146). Using co-cultured CHO cells expressing either human CTLA-4 or GFP-tagged human CD86, they observed transfer of GFP signal into CTLA-4 expressing cells, and its accumulation in the endolysosomal system, indicative of CD86 trans-endocytosis. Endocytosis-deficient CTLA-4 failed to induce trans-endocytosis of CD86-GFP and resulted in the accumulation of CD86 at cell contacts. These findings were confirmed using purified human Tregs incubated with DC where CD86 expression on the surface of the DC was reduced in the presence of Tregs but not effector T cells, and TCR stimulation increased the rate of trans-endocytosis (146). The most direct consequence of reduction of $\mathrm{B} 7$ proteins on the surface of APC is manifested in fewer and less prolonged interactions between APC and effector T cells $(147,148)$ reduced PKC- $\theta$ recruitment and activation in these cells (149) and, consequently, repression of IL-2 production by effector T cells (150). Recently, it has been shown that surface expression of CTLA-4 on effector T cells is sufficient for downregulation of CD86 expression from APCs (40).

Tregs display radically different synapse localization of CD28 and PKC- $\theta$ than effector T cells (summarized in Figure 2). In a stimulating planar lipid bilayer system, the recruitment of CD28 to the Treg IS is barely detectable, whereas CTLA- 4 is recruited robustly, in stark contrast to conventional CD4 T cells (141). Displacement of CD28 from Treg synapses by CTLA-4 coincides with the absence of PKC- $\theta$ clusters in the cSMAC zone of Treg synapses. Similarly, the switch of developmental program during the in vitro conversion of naïve CD4 T cells into Tregs results

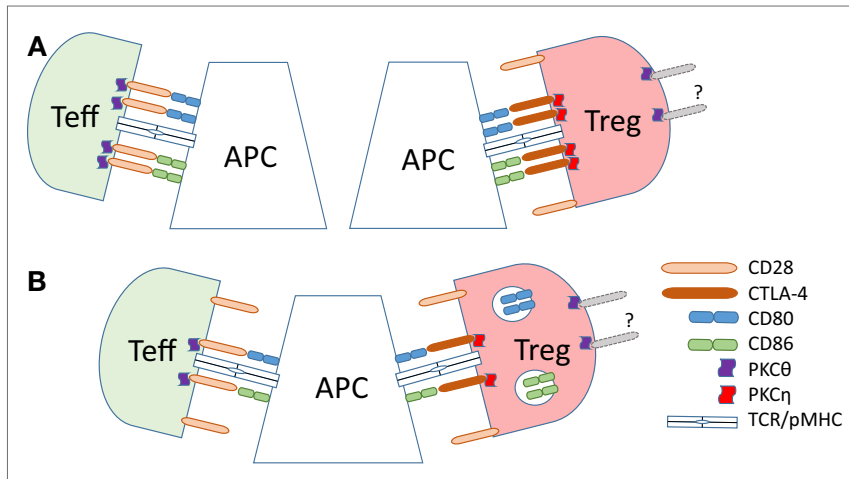

FIGURE 2 | Dynamics of B7 ligand recognition at effector and Treg IS. (A) B7 (CD80 or CD86) ligation leads to accumulation of CD28 and associated PKC- $\theta$ at the T effector cell IS. High-affinity B7 binding by CTLA-4 on Tregs leads to accumulation of CTLA-4 and the associated PKC- $\eta$ at the Treg IS, and exclusion of CD28 and PKC- $\theta$ from the IS. (B) CTLA-4 ligand binding in Tregs results in the trans-endocytosis of the B7 ligands. This reduces the amount of the $B 7$ ligands on the surface of the APC, leading to reduced co-stimulatory signals delivered to effector $\mathrm{T}$ cells.

in a loss of PKC- $\theta$ signal at the synapse. Correct localization of CTLA-4 to the IS is functionally important, as elongation of the extracellular domain of CTLA-4 resulted in a loss of its concentration in the synapse and reduction of suppressive activity of Tregs (141). In a lipid bilayer system, addition of CD80 or ICAM-1 to the bilayer increases the recruitment of PKC- $\theta$ to the synapse in both effector and Tregs, but stimulation through TCR strongly decreases the recruitment in Tregs (151). Reduction of PKC- $\theta$ activity results in increased Treg proliferation and elevated suppressive capacity (151).

An important insight into the signaling mechanism downstream of CTLA-4 recruitment to the Treg synapse was provided in a recent study by Kong et al. (152) which identified PKC- $\eta$ as the only PKC isoform physically interacting with CTLA-4. In Tregs, a phosphorylated form of PKC- $\eta$ binds constitutively to CTLA-4. PKC- $\eta$ localizes to the IS in close proximity to the TCR (152). Interaction between PKC- $\eta$ and CTLA-4 was found to be critical for Treg function. Phosphorylated serine residues S28, S32, and S317 of PKC- $\eta$ are responsible for the interaction with CTLA-4, and loss of S28 or S32 results in a strong inhibition of some Treg suppressive functions. The importance of PKC- $\eta$ was further emphasized by the finding that, although PKC- $\eta$-deficient Tregs expressed normal levels of functional LFA-1 required for the stabilization of contacts with APC, they showed a marked decrease in their ability to continuously clear CD86 from the APC surface. While CD86 clearance on first contact with APC was unaffected by the loss of PKC- $\eta$, the reduction of CD86 on reintroduced APC was substantially delayed (152). These findings suggest that PKC- $\eta$ is not directly involved in CTLA-4-induced trans-endocytosis, and that a feedback signaling mechanism from PKC $-\eta$ may be required for the recycling of CTLA-4 from the endolysosomal system. It remains to be elucidated whether or not the amount of surface-expressed CTLA-4 is reduced and its intracellular retention or lysosomal degradation is accelerated in the absence of PKC- $\eta$. In an earlier study, a deletion of amino 
acids 191-223 of the intracellular domain of CTLA-4 did not substantially affect the in vitro suppression of target $\mathrm{T}$ cell proliferation in the presence of CD3 crosslinking antibody and APC, or in vivo suppression in a colitis model (26). Kong et al. have shown that this deletion-mutant of CTLA-4 retains its association with PKC- $\eta$, suggesting that the remaining cytoplasmic portion (amino acids 182-191) of CTLA-4 is sufficient for suppressive signals using PKC- $\eta$.

Responses to CD80 and CD86 signals in effector T cells are largely similar $(153,154)$. By contrast, addition of anti-CD80 antibody or CTLA-4 Fab fragments to the co-culture of target $\mathrm{T}$ cells, DC, and prestimulated Tregs ablated the suppressive function of the latter, whereas addition of anti-CD86 or antiCD28 antibodies increased suppression to the same degree (155). Furthermore, blocking CD86 inhibited DC-induced division of Tregs, whereas blocking CD80 enhanced division (155). These data suggest that, in contrast to effector $\mathrm{T}$ cells, Tregs can effectively discriminate between CD80-CTLA-4 and CD86-CD28 signals.

\section{CTLA-4 IN REGULATION OF REGULATORY AND EFFECTOR T CELL SYNAPSE STABILITY AND CELL MOTILITY}

A growing body of evidence clearly suggests a role for CTLA-4 in regulation of synapse stability, duration of conjugation with APC and overall motility in Treg and Teff cells. Anti-CTLA-4 blocking antibody treatment has been shown to increase effector $\mathrm{T}$ cell motility in vitro $(122,156)$ and in vivo (157-159). Importantly, it has been reported that CTLA-4 ligation has different outcomes for synapse stability and motility of regulatory versus effector T cells $(122,160)$.

Regulatory $\mathrm{T}$ cells form a more stable IS than effector $\mathrm{T}$ cells, and this enhanced synapse stability has been implicated in CTLA-4-dependent downregulation of B7 cell surface expression by Tregs. In mixtures with conventional CD4 $\mathrm{T}$ cells of same specificity, TCR-transgenic Tregs preferentially bind to DCs and exclude conventional cells (161). Similarly, in a planar lipid bilayer system, Tregs form a more long-lived IS than do effector T cells of the same specificity (151). Addition of blocking CTLA-4 antibody does not overrule the competitive advantage of Tregs, but loss of LFA-1 results in its reversal, indicating that LFA-1 is at least partially responsible for the preferential binding of Tregs (161). Stimulated TCR-transgenic Tregs specifically reduce expression of both CD80 and CD86 on DC and to lesser degree $\mathrm{B}$ cells $(84,87,161,162)$. In the absence of stimulating peptide, the B7 molecules are not downregulated. CTLA-4-deficient Tregs as well as wild-type cells in the presence of CTLA-4 blocking antibody do not reduce B7 expression, and neither do Tregs from LFA-1 $1^{-1-}$ mice $(84,161)$, indicating that the formation of a stabilized, LFA-1 dependent, Treg-APC IS is important for the B7 downregulation.

B7 ligand recognition can modulate Treg motility. Tregs migrate rapidly on non-stimulating bilayers but slow down significantly, and increase contact time, upon encountering a TCR signal (TCR stop signal) $(160,163)$. Importantly, the stop signal required for the slowing down of Tregs is CTLA4-independent, as CTLA-4-deficient TCR-transgenic Tregs slowed down as efficiently as CTLA-4-sufficient cells in mixed culture with antigen-pulsed DC (160). Similarly, addition of blocking CTLA-4 antibody to Tregs on lipid bilayers containing CD80, pMHC, and ICAM-1 did not affect their motility (163). Although active displacement of CD28 from the IS by CTLA-4 precludes an active role for the former in the establishment and stabilization of Treg-APC synapses, a growing body of data indicates that CD28 may be important for the orchestration of Treg motility and contact half-life with APC prior to mature synapse formation. However, data on involvement of CD28 in stop signaling remain contradictory. While CD28-deficient Tregs stop normally in mixed culture (160), CD28-blocking antibody interfered with the stop signal (163). Specific loss of CD28 in Tregs reduces surface expression of CTLA-4 on these cells and results in reduced suppressive capacity and systemic autoimmunity (71), indicating that tonic signaling input downstream of transient $\mathrm{B} 7-\mathrm{CD} 28$ interactions may regulate recycling of CTLA-4 protein. CD86 and CD28 input is also important for DC-induced proliferation of Tregs (155).

Unlike Tregs, effector $\mathrm{T}$ cells are sensitive to CTLA-4dependent reversal of the TCR stop signal. In the first report of CTLA-4 dependent reversal of TCR stop signal, Schneider et al. (156) used anti-CTLA-4 stimulation and observed that it enhanced effector $\mathrm{T}$ cell motility on LFA-1-coated plates. Moreover, anti-CD3 antibody induced reduction in $\mathrm{T}$ cell motility, but a combination of anti-CD3 and anti-CTLA-4 did not elicit this stop signal. In the same study, CTLA-4 expression on effector $\mathrm{T}$ cells increased their motility and reduced their contact time with APCs in the context of antigen recognition in the lymph node (156). CTLA-4 was also shown to reverse the TCR stop signal in human effector T cell clones in vitro (122). Additionally, CTLA-4 antibody treatment enhanced effector T cell motility in the context of an anti-tumor response $(158,159)$. However, two other 2 photon imaging studies did not report this differential effect of CTLA-4 blockade on regulatory and effector CD4+ T cell populations $(157,164)$. A study using a mouse model of $\mathrm{T}$ cell responses in pancreatic islet grafts reported that CTLA-4 blockade slightly increased motility of both effector and Treg populations, suggesting that CTLA- 4 marginally reduces CD4+ T cell motility in vivo (157). However, the imaging performed in this study was conducted in an immunoprivileged site (the islet grafts were injected into the anterior chamber of the eye), which could have affected the cellular motility observed. Moreover, the role of TCR signal in the reported effector and Treg motility changes is unknown, as this study observed direct interactions between pancreatic peptide-specific TCR-transgenic CD4 T cells and islet cells, which do not express MHC class II and, thus, cannot present antigenic peptide to T cells. Another study investigating motility of tolerized diabetogenic CD4+ T cells reported no effect of CTLA- 4 blockade on T cell motility (164). However, this study did not differentiate between effector and Treg populations, and the effect on CTLA-4 on control, nontolerized diabetogenic T cells was not reported (164). Overall, the results from these two studies indicate that CTLA-4 has limited effect on motility of self-antigen-specific CD4+ effector T cells, 
similar to its relatively limited effect on Treg motility. Given that the natural Treg lineage consists of self-reactive T cells (165), this raises an interesting possibility that the role of CTLA-4 in regulation of synapse stability and cellular motility of CD4+ T cells depends on their TCR specificity.

Importantly, the different effects of CTLA-4 blockade on effector $\mathrm{T}$ cells and Tregs have also been observed in a recent study using 2 photon microscopy to examine the behavior of the two CD4+ T cell populations in intact lymph nodes (13). CTLA-4 blockade increased Treg motility but decreased effector T cell motility in the presence of antigen, consistent with the proposed role of CTLA-4 in reversal of TCR-induced motility stop in effector, but not regulatory, T cell populations. Anti-CTLA-4 antibody administration increased effector $\mathrm{T}$ cell contact time with DCs presenting antigen, but reduced Treg contacts with DCs, strongly suggesting that CTLA-4 has opposing effects on effector and Treg IS stability in vivo. However, as CTLA-4 blockade increased the steady-state motility of Tregs, but had no effect on effector $\mathrm{T}$ cell motility in the absence of antigenic stimulation, the reduced effector T cell motility and enhanced clustering with DCs after anti-CTLA-4 treatment could be the result of exclusion of Tregs from T cell: DC clusters, rather than a direct effect of CTLA-4 on effector T cells. Interestingly, this study also reported regulatory-effector $\mathrm{T}$ cell contacts that were dependent on Treg recognition of B7 expressed on activated $\mathrm{T}$ cells (13), suggesting that CTLA-4: B7 interaction plays a role in regulation of $\mathrm{T}$ : $\mathrm{T}$ cell synapse formation and facilitates Tregmediated suppression.

The molecular mechanism of CTLA-4-dependent regulation of effector T cell synapse stability and cellular motility is unknown. The initial observation that anti-CTLA-4 treatment enhances effector T cell motility on LFA-1 coated slides and in response to TCR signal was originally interpreted as evidence for an as yet unidentified CTLA-4-induced signal overriding the TCR stop signal (156). CTLA-4 ligation was shown to reduce IS stability $(122,166)$ and decrease cytoskeletal rearrangements at the synapse (166) through an unknown molecular mechanism. CTLA-4 ligation was also shown to activate the small G protein Rap1 $(167,168)$, and CTLA-4-induced Rap1 activity was linked to destabilization of the IS (53). However, CTLA-4 mediated increase in Rap1 activity has also been linked to enhanced LFA-1 mediated adhesion (167-169), which is difficult to reconcile with the reduced synapse stability. Moreover, an in vivo study reported that intact anti-CTLA-4 antibody and its Fab fragments enhanced effector $\mathrm{T}$ cell motility equally well, suggesting that CTLA-4-dependent signaling did not play a role in the motility enhancement (158). Given the role of CD28 in regulation of cytoskeletal dynamics, it is plausible that CTLA-4 may reduce synapse stability and enhance T cell motility through counteracting CD28-mediated cytoskeletal rearrangement through competition for B7 ligand binding. However, there is conflicting evidence to support this hypothesis. It has been reported that the CTLA-4-dependent increase in motility does not require CD28 expression (160), and that the cytoplasmic region of CTLA-4 is required for regulation of T cell motility (166), suggesting a role for as yet unidentified CTLA-4-dependent signaling.

\section{CONCLUSION}

B7 ligand recognition plays an important role in orchestrating the IS architecture in both effector T cells and Tregs. During recognition of antigen, B7 ligand binding induces CD28 localization to distinct TCR ${ }^{\text {low }}$ clusters within the central region of the effector $\mathrm{T}$ cell IS. This CD28 recruitment can be counteracted by CTLA-4 through competition for ligand binding and/or by removal of co-stimulatory ligands through trans-endocytosis. CD28 recruitment to the IS induces PKC- $\theta$ localization to the center of the IS, through interactions between PKC- $\theta$ V3 hinge region and the proline-rich motif on the cytoplasmic tail of CD28. CD28 ligation leads to cytoskeletal rearrangements at the IS through CD28dependent control of multiple pathways regulating cytoskeletal dynamics: Vav1 and cofilin activation, filamin A binding, and regulation of actin-uncapping proteins. CD28-dependent PKC- $\theta$ recruitment and modulation of cytoskeleton plays a critical role in regulation of effector T cell functions. CTLA-4 is a negative regulator of effector $\mathrm{T}$ cell functions, and there is evidence that CTLA-4 can reduce effector T cell IS stability through reversal of the TCR-induced stop signal.

While signaling through CD28 is important for steady-state homeostasis, motility, target recognition, and division of Tregs, their activation results in active exclusion of CD28 and PKC- $\theta$ and recruitment of CTLA-4 and PKC- $\eta$ to the synapse. Both phenomena are required for the suppressive function. In contrast to conventional CD4 T cells, CTLA- 4 and PKC- $\eta$ act as positive regulators of Treg function. Since CTLA-4 binds to B7 proteins with significantly higher affinity than CD28 and exclusively activates PKC- $\eta$ (152), it is reasonable to conclude that its affinity alone may be sufficient to initiate the exclusion of CD28 from potential B7 binding sites. Preferential activation of PKC- $\eta$ is then a direct outcome of exclusive CTLA-4 recruitment. Higher affinity of CTLA-4-B7 interactions also explains why Tregs are capable of actively recruiting B7 proteins to the synapse, while effector T cells are not (170). Increased affinity of B7-receptor interaction and recruitment of $\mathrm{B} 7$ proteins to the synapse also contribute to more long-lived, stable synapses between Tregs and APCs as compared to conventional T cells.

B7 ligand recognition induces dissimilar immune synapse architecture in mature effector $\mathrm{T}$ cells and Tregs, but its role in regulation of the immune synapse dynamics at different stages of $\mathrm{T}$ cell development is poorly understood. It remains to be determined if the IS formed by pre-selection thymocytes shows the central localization of CD28 and/or PKC- $\theta$, similar to that observed in effector T cells. Given that immature thymocytes do not show the centralized TCR accumulation at the immune synapse $(171,172)$, and that PKC- $\theta$ is not required for NFKB activation in thymocytes (173), it is likely that CD28/PKC- $\theta$ dynamics at the thymocyte IS are different to the dynamics in mature effector T cells. At the other end of the T cell's lifetime, CD28/PKC- $\theta$ immune synapse dynamics in exhausted T cells or $\mathrm{T}$ cells from aged individuals are very poorly understood. Anergic murine $\mathrm{T}$ cells were shown to display unimpaired $\mathrm{PKC}-\theta$ recruitment (174), but loss of CD28 from human T cells due to repeated antigen exposure or aging may have implications on PKC- $\theta$ synapse localization, resulting in altered kinetics and architecture of 
the synapse, and changes in downstream signaling. Furthermore, despite the massive amount of data on CTLA- 4 biology and the growing importance of the CTLA-4 pathway in immunotherapy, its role in regulation of $\mathrm{T}$ cell functions and IS dynamics remains incompletely understood. Since activated effector $\mathrm{T}$ cells express CTLA-4 and since surface CTLA-4 is capable of B7 extraction from target membranes regardless of cell type (146), it will be intriguing further to explore the potential role of CTLA- 4 in the effector $\mathrm{T}$ cell-intrinsic restriction of strength and/or duration of activation, independently of bystander suppression by Tregexpressed CTLA-4. At the signaling level, given the role of CD28 signaling in regulating cytoskeleton dynamics at the IS, CTLA-4 can likely counteract these CD28-mediated pathways, either indirectly through reducing levels of B7 proteins on APCs, or directly through interactions yet unidentified with other binding partners. PKC- $\eta$ is a likely candidate, as Tregs lacking PKC- $\eta$ showed enhanced conjugation with DCs, and the CTLA-4-PKC$\eta$ complex has been shown to interact with the focal adhesion

\section{REFERENCES}

1. Postow MA, Callahan MK, Wolchok JD. Immune checkpoint blockade in cancer therapy. J Clin Oncol (2015) 33:1974-82. doi:10.1200/JCO.2014.59.4358

2. Sadelain M, Brentjens R, Riviere I. The basic principles of chimeric antigen receptor design. Cancer Discov (2013) 3:388-98. doi:10.1158/2159-8290. CD-12-0548

3. Suntharalingam G, Perry MR, Ward S, Brett SJ, Castello-Cortes A, Brunner $\mathrm{MD}$, et al. Cytokine storm in a phase 1 trial of the anti-CD28 monoclonal antibody TGN1412. $N$ Engl J Med (2006) 355:1018-28. doi:10.1056/ NEJMoa063842

4. Dustin ML. The immunological synapse. Cancer Immunol Res (2014) 2:1023-33. doi:10.1158/2326-6066.CIR-14-0161

5. Fooksman DR, Vardhana S, Vasiliver-Shamis G, Liese J, Blair DA, Waite $\mathrm{J}$, et al. Functional anatomy of $\mathrm{T}$ cell activation and synapse formation. Annu Rev Immunol (2010) 28:79-105. doi:10.1146/ annurev-immunol-030409-101308

6. Xie J, Tato CM, Davis MM. How the immune system talks to itself: the varied role of synapses. Immunol Rev (2013) 251:65-79. doi:10.1111/imr.12017

7. Saito $T$, Yokosuka $T$, Hashimoto-Tane A. Dynamic regulation of $T$ cell activation and co-stimulation through TCR-microclusters. FEBS Lett (2010) 584:4865-71. doi:10.1016/j.febslet.2010.11.036

8. Ikemizu S, Gilbert RJ, Fennelly JA, Collins AV, Harlos K, Jones EY, et al. Structure and dimerization of a soluble form of B7-1. Immunity (2000) 12:51-60. doi:10.1016/S1074-7613(00)80158-2

9. Zhang X, Schwartz JC, Almo SC, Nathenson SG. Crystal structure of the receptor-binding domain of human B7-2: insights into organization and signaling. Proc Natl Acad Sci U S A (2003) 100:2586-91. doi:10.1073/ pnas. 252771499

10. Bhatia S, Edidin M, Almo SC, Nathenson SG. Different cell surface oligomeric states of B7-1 and B7-2: implications for signaling. Proc Natl Acad Sci U S A (2005) 102:15569-74. doi:10.1073/pnas.0507257102

11. Bhatia S, Sun K, Almo SC, Nathenson SG, Hodes RJ. Dynamic equilibrium of B7-1 dimers and monomers differentially affects immunological synapse formation and $\mathrm{T}$ cell activation in response to TCR/CD28 stimulation. J Immunol (2010) 184:1821-8. doi:10.4049/jimmunol.0902869

12. Azuma M, Yssel H, Phillips JH, Spits H, Lanier LL. Functional expression of B7/BB1 on activated T lymphocytes. J Exp Med (1993) 177:845-50. doi:10.1084/jem.177.3.845

13. Matheu MP, Othy S, Greenberg ML, Dong TX, Schuijs M, Deswarte K, et al. Imaging regulatory $\mathrm{T}$ cell dynamics and CTLA4-mediated suppression of $\mathrm{T}$ cell priming. Nat Commun (2015) 6:6219. doi:10.1038/ncomms7219

14. Prabhu Das MR, Zamvil SS, Borriello F, Weiner HL, Sharpe AH, Kuchroo VK. Reciprocal expression of co-stimulatory molecules, B7-1 and B7-2, complex components PAK2 and GIT2, as well as with the guanine nucleotide exchange factor $\alpha$ PIX (152), with a known role in regulating cytoskeletal dynamics (175). Better understanding of the effect of B7 ligand recognition on the IS dynamics at different stages of $\mathrm{T}$ cell development and in different $\mathrm{T}$ cell subsets is likely to have significant implications for the development of novel immunotherapy strategies.

\section{AUTHOR CONTRIBUTIONS}

VR and JB wrote the initial draft of this review. VR, NG, and JB rewrote and edited the article.

\section{FUNDING}

This work was funded by grants from the Ministry of Education (MOE2014-T2-1-136) and National Medical Research Foundation (CBRG0064/2014).

on murine T cells following activation. Eur J Immunol (1995) 25:207-11. doi:10.1002/eji.1830250134

15. van der Merwe PA, Bodian DL, Daenke S, Linsley P, Davis SJ. CD80 (B7-1) binds both CD28 and CTLA-4 with a low affinity and very fast kinetics. J Exp Med (1997) 185:393-403. doi:10.1084/jem.185.3.393

16. Fagnoni FF, Vescovini R, Mazzola M, Bologna G, Nigro E, Lavagetto $\mathrm{G}$, et al. Expansion of cytotoxic CD8+ CD28- T cells in healthy ageing people, including centenarians. Immunology (1996) 88:501-7. doi:10.104 6/j.1365-2567.1996.d01-689.x

17. Vallejo AN, Nestel AR, Schirmer M, Weyand CM, Goronzy JJ. Aging-related deficiency of CD28 expression in CD4+ T cells is associated with the loss of gene-specific nuclear factor binding activity. J Biol Chem (1998) 273:8119-29. doi:10.1074/jbc.273.14.8119

18. Weng NP, Akbar AN, Goronzy J. CD28(-) T cells: their role in the age-associated decline of immune function. Trends Immunol (2009) 30:306-12. doi:10.1016/j.it.2009.03.013

19. Ortiz-Suarez A, Miller RA. A subset of CD8 memory T cells from old mice have high levels of CD28 and produce IFN-gamma. Clin Immunol (2002) 104:282-92. doi:10.1006/clim.2002.5221

20. Valenzuela HF, Effros RB. Divergent telomerase and CD28 expression patterns in human CD4 and CD8 T cells following repeated encounters with the same antigenic stimulus. Clin Immunol (2002) 105:117-25. doi:10.1006/ clim.2002.5271

21. Vallejo AN, Brandes JC, Weyand CM, Goronzy JJ. Modulation of CD28 expression: distinct regulatory pathways during activation and replicative senescence. J Immunol (1999) 162:6572-9.

22. Borthwick NJ, Lowdell M, Salmon M, Akbar AN. Loss of CD28 expression on CD8(+) T cells is induced by IL-2 receptor gamma chain signalling cytokines and type I IFN, and increases susceptibility to activation-induced apoptosis. Int Immunol (2000) 12:1005-13. doi:10.1093/intimm/12.7.1005

23. Metzler B, Burkhart C, Wraith DC. Phenotypic analysis of CTLA-4 and CD28 expression during transient peptide-induced $\mathrm{T}$ cell activation in vivo. Int Immunol (1999) 11:667-75. doi:10.1093/intimm/11.5.667

24. Lindsten T, Lee KP, Harris ES, Petryniak B, Craighead N, Reynolds PJ, et al. Characterization of CTLA-4 structure and expression on human T cells. J Immunol (1993) 151:3489-99.

25. Perkins D, Wang Z, Donovan C, He H, Mark D, Guan G, et al. Regulation of CTLA-4 expression during T cell activation. J Immunol (1996) 156:4154-9.

26. Tai X, Van Laethem F, Pobezinsky L, Guinter T, Sharrow SO, Adams A, et al. Basis of CTLA-4 function in regulatory and conventional CD4(+) T cells. Blood (2012) 119:5155-63. doi:10.1182/blood-2011-11-388918

27. Hori S, Nomura T, Sakaguchi S. Control of regulatory T cell development by the transcription factor Foxp3. Science (2003) 299:1057-61. doi:10.1126/ science. 1079490 
28. Wu Y, Borde M, Heissmeyer V, Feuerer M, Lapan AD, Stroud JC, et al. FOXP3 controls regulatory $\mathrm{T}$ cell function through cooperation with NFAT. Cell (2006) 126:375-87. doi:10.1016/j.cell.2006.05.042

29. Zheng Y, Josefowicz SZ, Kas A, Chu TT, Gavin MA, Rudensky AY. Genomewide analysis of Foxp3 target genes in developing and mature regulatory $\mathrm{T}$ cells. Nature (2007) 445:936-40. doi:10.1038/nature05563

30. Chuang E, Alegre ML, Duckett CS, Noel PJ, Vander Heiden MG, Thompson CB. Interaction of CTLA- 4 with the clathrin-associated protein AP50 results in ligand-independent endocytosis that limits cell surface expression. J Immunol (1997) 159:144-51.

31. Flores-Borja F, Jury EC, Mauri C, Ehrenstein MR. Defects in CTLA-4 are associated with abnormal regulatory $\mathrm{T}$ cell function in rheumatoid arthritis. Proc Natl Acad Sci US A (2008) 105:19396-401. doi:10.1073/pnas.0806855105

32. Qureshi OS, Kaur S, Hou TZ, Jeffery LE, Poulter NS, Briggs Z, et al. Constitutive clathrin-mediated endocytosis of CTLA-4 persists during $\mathrm{T}$ cell activation. J Biol Chem (2012) 287:9429-40. doi:10.1074/jbc.M111.304329

33. Shiratori T, Miyatake S, Ohno H, Nakaseko C, Isono K, Bonifacino JS, et al. Tyrosine phosphorylation controls internalization of CTLA-4 by regulating its interaction with clathrin-associated adaptor complex AP-2. Immunity (1997) 6:583-9. doi:10.1016/S1074-7613(00)80346-5

34. Zhang Y, Allison JP. Interaction of CTLA-4 with AP50, a clathrin-coated pit adaptor protein. Proc Natl Acad Sci U S A (1997) 94:9273-8. doi:10.1073/ pnas.94.17.9273

35. Schneider H, Martin M, Agarraberes FA, Yin L, Rapoport I, Kirchhausen T, et al. Cytolytic T lymphocyte-associated antigen-4 and the TCR zeta/CD3 complex, but not CD28, interact with clathrin adaptor complexes AP-1 and AP-2. J Immunol (1999) 163:1868-79.

36. Schneider H, Rudd CE. Diverse mechanisms regulate the surface expression of immunotherapeutic target ctla-4. Front Immunol (2014) 5:619. doi:10.3389/fimmu.2014.00619

37. Banton MC, Inder KL, Valk E, Rudd CE, Schneider H. Rab8 binding to immune cell-specific adaptor LAX facilitates formation of trans-Golgi network-proximal CTLA-4 vesicles for surface expression. Mol Cell Biol (2014) 34:1486-99. doi:10.1128/MCB.01331-13

38. Valk E, Leung R, Kang H, Kaneko K, Rudd CE, Schneider H. T cell receptor-interacting molecule acts as a chaperone to modulate surface expression of the CTLA-4 coreceptor. Immunity (2006) 25:807-21. doi:10.1016/j. immuni.2006.08.024

39. Lo B, Zhang K, Lu W, Zheng L, Zhang Q, Kanellopoulou C, et al. AUTOIMMUNE DISEASE. Patients with LRBA deficiency show CTLA4 loss and immune dysregulation responsive to abatacept therapy. Science (2015) 349:436-40. doi:10.1126/science.aaa1663

40. Hou TZ, Qureshi OS, Wang CJ, Baker J, Young SP, Walker LS, et al. A transendocytosis model of CTLA-4 function predicts its suppressive behavior on regulatory T cells. J Immunol (2015) 194:2148-59. doi:10.4049/ jimmunol.1401876

41. Isakov N, Altman A. PKC-theta-mediated signal delivery from the TCR/ CD28 surface receptors. Front Immunol (2012) 3:273. doi:10.3389/ fimmu.2012.00273

42. Isakov N, Altman A. Regulation of immune system cell functions by protein kinase C. Front Immunol (2013) 4:384. doi:10.3389/fimmu.2013.00384

43. Margulies DH. CD28, costimulator or agonist receptor? J Exp Med (2003) 197:949-53. doi:10.1084/jem.20030303

44. Sharpe AH, Freeman GJ. The B7-CD28 superfamily. Nat Rev Immunol (2002) 2:116-26. doi:10.1038/nri727

45. Stamper CC, Zhang Y, Tobin JF, Erbe DV, Ikemizu S, Davis SJ, et al. Crystal structure of the B7-1/CTLA-4 complex that inhibits human immune responses. Nature (2001) 410:608-11. doi:10.1038/35069118

46. Morton PA, Fu XT, Stewart JA, Giacoletto KS, White SL, Leysath CE, et al. Differential effects of CTLA-4 substitutions on the binding of human CD80 (B7-1) and CD86 (B7-2). J Immunol (1996) 156:1047-54.

47. Peach RJ, Bajorath J, Brady W, Leytze G, Greene J, Naemura J, et al. Complementarity determining region 1 (CDR1)- and CDR3-analogous regions in CTLA-4 and CD28 determine the binding to B7-1. J Exp Med (1994) 180:2049-58. doi:10.1084/jem.180.6.2049

48. Pentcheva-Hoang T, Egen JG, Wojnoonski K, Allison JP. B7-1 and B7-2 selectively recruit CTLA-4 and CD28 to the immunological synapse. Immunity (2004) 21:401-13. doi:10.1016/j.immuni.2004.06.017
49. Boomer JS, Green JM. An enigmatic tail of CD28 signaling. Cold Spring Harb Perspect Biol (2010) 2:a002436. doi:10.1101/cshperspect.a002436

50. Pages F, Ragueneau M, Rottapel R, Truneh A, Nunes J, Imbert J, et al. Binding of phosphatidylinositol-3-OH kinase to $\mathrm{CD} 28$ is required for T-cell signalling. Nature (1994) 369:327-9. doi:10.1038/369327a0

51. Raab M, Cai YC, Bunnell SC, Heyeck SD, Berg LJ, Rudd CE. p56Lck and p59Fyn regulate CD28 binding to phosphatidylinositol 3-kinase, growth factor receptor-bound protein GRB-2, and T cell-specific protein-tyrosine kinase ITK: implications for T-cell costimulation. Proc Natl Acad Sci U S A (1995) 92:8891-5. doi:10.1073/pnas.92.19.8891

52. Truitt KE, Hicks CM, Imboden JB. Stimulation of CD28 triggers an association between CD28 and phosphatidylinositol 3-kinase in Jurkat T cells. J Exp Med (1994) 179:1071-6. doi:10.1084/jem.179.3.1071

53. Ellis JH, Ashman C, Burden MN, Kilpatrick KE, Morse MA, Hamblin PA. GRID: a novel Grb-2-related adapter protein that interacts with the activated $\mathrm{T}$ cell costimulatory receptor CD28. J Immunol (2000) 164:5805-14. doi:10.4049/jimmunol.164.11.5805

54. Holdorf AD, Green JM, Levin SD, Denny MF, Straus DB, Link V, et al. Proline residues in CD28 and the Src homology (SH)3 domain of Lck are required for T cell costimulation. J Exp Med (1999) 190:375-84. doi:10.1084/ jem.190.3.375

55. Okkenhaug K, Rottapel R. Grb2 forms an inducible protein complex with CD28 through a Src homology 3 domain-proline interaction. J Biol Chem (1998) 273:21194-202. doi:10.1074/jbc.273.33.21194

56. Marengere LE, Okkenhaug K, Clavreul A, Couez D, Gibson S, Mills GB, et al. The SH3 domain of Itk/Emt binds to proline-rich sequences in the cytoplasmic domain of the $\mathrm{T}$ cell costimulatory receptor CD28. J Immunol (1997) 159:3220-9.

57. Dodson LF, Boomer JS, Deppong CM, Shah DD, Sim J, Bricker TL, et al. Targeted knock-in mice expressing mutations of CD28 reveal an essential pathway for costimulation. Mol Cell Biol (2009) 29:3710-21. doi:10.1128/ MCB.01869-08

58. Boomer JS, Deppong CM, Shah DD, Bricker TL, Green JM. Cutting edge: a double-mutant knockin of the CD28 YMNM and PYAP motifs reveals a critical role for the YMNM motif in regulation of $\mathrm{T}$ cell proliferation and Bcl-xL expression. J Immunol (2014) 192:3465-9. doi:10.4049/ jimmunol.1301240

59. Rudensky AY. Regulatory T cells and Foxp3. Immunol Rev (2011) 241:260-8. doi:10.1111/j.1600-065X.2011.01018.x

60. Sakaguchi S, Wing K, Onishi Y, Prieto-Martin P, Yamaguchi T. Regulatory $\mathrm{T}$ cells: how do they suppress immune responses? Int Immunol (2009) 21:1105-11. doi:10.1093/intimm/dxp095

61. Asseman C, Mauze S, Leach MW, Coffman RL, Powrie F. An essential role for interleukin 10 in the function of regulatory $\mathrm{T}$ cells that inhibit intestinal inflammation. J Exp Med (1999) 190:995-1004. doi:10.1084/ jem.190.7.995

62. Read S, Malmstrom V, Powrie F. Cytotoxic T lymphocyte-associated antigen 4 plays an essential role in the function of $\mathrm{CD} 25(+) \mathrm{CD} 4(+)$ regulatory cells that control intestinal inflammation. J Exp Med (2000) 192:295-302. doi:10.1084/jem.192.2.295

63. Pandiyan P, Zheng L, Ishihara S, Reed J, Lenardo MJ. CD4+CD25+Foxp3+ regulatory $\mathrm{T}$ cells induce cytokine deprivation-mediated apoptosis of effector CD4+ T cells. Nat Immunol (2007) 8:1353-62. doi:10.1038/ni1536

64. Salomon B, Lenschow DJ, Rhee L, Ashourian N, Singh B, Sharpe A, et al. $\mathrm{B} 7 / \mathrm{CD} 28$ costimulation is essential for the homeostasis of the CD4+CD25+ immunoregulatory $\mathrm{T}$ cells that control autoimmune diabetes. Immunity (2000) 12:431-40. doi:10.1016/S1074-7613(00)80195-8

65. Tang Q, Henriksen KJ, Boden EK, Tooley AJ, Ye J, Subudhi SK, et al. Cutting edge: $\mathrm{CD} 28$ controls peripheral homeostasis of $\mathrm{CD} 4+\mathrm{CD} 25+$ regulatory T cells. J Immunol (2003) 171:3348-52. doi:10.4049/jimmunol.171.7.3348

66. Read S, Greenwald R, Izcue A, Robinson N, Mandelbrot D, Francisco L, et al. Blockade of CTLA-4 on CD4+CD25+ regulatory T cells abrogates their function in vivo. JImmunol (2006) 177:4376-83. doi:10.4049/ jimmunol.177.7.4376

67. Tai X, Cowan M, Feigenbaum L, Singer A. CD28 costimulation of developing thymocytes induces Foxp3 expression and regulatory $\mathrm{T}$ cell differentiation independently of interleukin 2. Nat Immunol (2005) 6:152-62. doi: $10.1038 /$ ni1 160 
68. Jordan MS, Boesteanu A, Reed AJ, Petrone AL, Holenbeck AE, Lerman MA, et al. Thymic selection of $\mathrm{CD} 4+\mathrm{CD} 25+$ regulatory $\mathrm{T}$ cells induced by an agonist self-peptide. Nat Immunol (2001) 2:301-6. doi:10.1038/86302

69. McKean DJ, Huntoon CJ, Bell MP, Tai X, Sharrow S, Hedin KE, et al. Maturation versus death of developing double-positive thymocytes reflects competing effects on Bcl-2 expression and can be regulated by the intensity of CD28 costimulation. J Immunol (2001) 166:3468-75. doi:10.4049/ jimmunol.166.5.3468

70. Punt JA, Osborne BA, Takahama Y, Sharrow SO, Singer A. Negative selection of $\mathrm{CD} 4+\mathrm{CD} 8+$ thymocytes by $\mathrm{T}$ cell receptor-induced apoptosis requires a costimulatory signal that can be provided by CD28. J Exp Med (1994) 179:709-13. doi:10.1084/jem.179.2.709

71. Zhang R, Huynh A, Whitcher G, Chang J, Maltzman JS, Turka LA. An obligate cell-intrinsic function for CD28 in Tregs. J Clin Invest (2013) 123:580-93. doi:10.1172/JCI65013

72. Lio CW, Dodson LF, Deppong CM, Hsieh CS, Green JM. CD28 facilitates the generation of Foxp3(-) cytokine responsive regulatory $\mathrm{T}$ cell precursors. J Immunol (2010) 184:6007-13. doi:10.4049/jimmunol.1000019

73. Badour K, McGavin MK, Zhang J, Freeman S, Vieira C, Filipp D, et al. Interaction of the Wiskott-Aldrich syndrome protein with sorting nexin 9 is required for CD28 endocytosis and cosignaling in T cells. Proc Natl Acad Sci U S A (2007) 104:1593-8. doi:10.1073/pnas.0610543104

74. Tang Q, Henriksen KJ, Bi M, Finger EB, Szot G, Ye J, et al. In vitro-expanded antigen-specific regulatory $\mathrm{T}$ cells suppress autoimmune diabetes. J Exp Med (2004) 199:1455-65. doi:10.1084/jem.20040139

75. Guo F, Iclozan C, Suh WK, Anasetti C, Yu XZ. CD28 controls differentiation of regulatory T cells from naive CD4 T cells. J Immunol (2008) 181:2285-91. doi:10.4049/jimmunol.181.4.2285

76. Liang S, Alard P, Zhao Y, Parnell S, Clark SL, Kosiewicz MM. Conversion of CD4+ CD25- cells into CD4+ CD25+ regulatory T cells in vivo requires B7 costimulation, but not the thymus. J Exp Med (2005) 201:127-37. doi:10.1084/jem.20041201

77. Chen W, Jin W, Hardegen N, Lei KJ, Li L, Marinos N, et al. Conversion of peripheral $\mathrm{CD} 4+\mathrm{CD} 25$ - naive $\mathrm{T}$ cells to $\mathrm{CD} 4+\mathrm{CD} 25+$ regulatory $\mathrm{T}$ cells by TGF-beta induction of transcription factor Foxp3. J Exp Med (2003) 198:1875-86. doi:10.1084/jem.20030152

78. Tivol EA, Borriello F, Schweitzer AN, Lynch WP, Bluestone JA, Sharpe AH. Loss of CTLA-4 leads to massive lymphoproliferation and fatal multiorgan tissue destruction, revealing a critical negative regulatory role of CTLA-4. Immunity (1995) 3:541-7. doi:10.1016/1074-7613(95)90125-6

79. Waterhouse P, Penninger JM, Timms E, Wakeham A, Shahinian A, Lee KP, et al. Lymphoproliferative disorders with early lethality in mice deficient in Ctla-4. Science (1995) 270:985-8. doi:10.1126/science.270.5238.985

80. Chambers CA, Sullivan TJ, Allison JP. Lymphoproliferation in CTLA-4deficient mice is mediated by costimulation-dependent activation of $\mathrm{CD} 4+$ T cells. Immunity (1997) 7:885-95. doi:10.1016/S1074-7613(00)80406-9

81. Friedline RH, Brown DS, Nguyen H, Kornfeld H, Lee J, Zhang Y, et al. CD4+ regulatory T cells require CTLA- 4 for the maintenance of systemic tolerance. J Exp Med (2009) 206:421-34. doi:10.1084/jem.20081811

82. Liu Z, Geboes K, Hellings P, Maerten P, Heremans H, Vandenberghe P, et al. B7 interactions with CD28 and CTLA- 4 control tolerance or induction of mucosal inflammation in chronic experimental colitis. J Immunol (2001) 167:1830-8. doi:10.4049/jimmunol.167.3.1830

83. Sojka DK, Hughson A, Fowell DJ. CTLA-4 is required by CD4+CD25+ Treg to control CD4+ T-cell lymphopenia-induced proliferation. Eur J Immunol (2009) 39:1544-51. doi:10.1002/eji.200838603

84. Wing K, Onishi Y, Prieto-Martin P, Yamaguchi T, Miyara M, Fehervari Z, et al. CTLA-4 control over Foxp3+ regulatory T cell function. Science (2008) 322:271-5. doi:10.1126/science.1160062

85. Verhagen J, Genolet R, Britton GJ, Stevenson BJ, Sabatos-Peyton CA, Dyson J, et al. CTLA-4 controls the thymic development of both conventional and regulatory T cells through modulation of the TCR repertoire. Proc Natl Acad Sci U S A (2013) 110:E221-30. doi:10.1073/pnas. 1208573110

86. Cilio CM, Daws MR, Malashicheva A, Sentman CL, Holmberg D. Cytotoxic T lymphocyte antigen 4 is induced in the thymus upon in vivo activation and its blockade prevents anti-CD3-mediated depletion of thymocytes. J Exp Med (1998) 188:1239-46. doi:10.1084/jem.188.7.1239

87. Schmidt EM, Wang CJ, Ryan GA, Clough LE, Qureshi OS, Goodall M, et al. Ctla- 4 controls regulatory $\mathrm{T}$ cell peripheral homeostasis and is required for suppression of pancreatic islet autoimmunity. J Immunol (2009) 182:274-82. doi:10.4049/jimmunol.182.1.274

88. Barnes MJ, Griseri T, Johnson AM, Young W, Powrie F, Izcue A. CTLA-4 promotes Foxp3 induction and regulatory $\mathrm{T}$ cell accumulation in the intestinal lamina propria. Mucosal Immunol (2013) 6:324-34. doi:10.1038/ mi.2012.75

89. Andres PG, Howland KC, Dresnek D, Edmondson S, Abbas AK, Krummel MF. CD28 signals in the immature immunological synapse. J Immunol (2004) 172:5880-6. doi:10.4049/jimmunol.172.10.5880

90. Yokosuka T, Kobayashi W, Sakata-Sogawa K, Takamatsu M, Hashimoto-Tane A, Dustin ML, et al. Spatiotemporal regulation of $\mathrm{T}$ cell costimulation by TCR-CD28 microclusters and protein kinase $\mathrm{C}$ theta translocation. Immunity (2008) 29:589-601. doi:10.1016/j.immuni.2008.08.011

91. Yokosuka T, Saito T. Dynamic regulation of T-cell costimulation through TCR-CD28 microclusters. Immunol Rev (2009) 229:27-40. doi:10.1111/j.1600-065X.2009.00779.x

92. Shen K, Thomas VK, Dustin ML, Kam LC. Micropatterning of costimulatory ligands enhances CD4+ T cell function. Proc Natl Acad Sci U S A (2008) 105:7791-6. doi:10.1073/pnas.0710295105

93. Tseng SY, Liu M, Dustin ML. CD80 cytoplasmic domain controls localization of CD28, CTLA-4, and protein kinase Ctheta in the immunological synapse. J Immunol (2005) 175:7829-36. doi:10.4049/jimmunol.175.12.7829

94. Doty RT, Clark EA. Subcellular localization of CD80 receptors is dependent on an intact cytoplasmic tail and is required for CD28-dependent $\mathrm{T}$ cell costimulation. J Immunol (1996) 157:3270-9.

95. Doty RT, Clark EA. Two regions in the CD80 cytoplasmic tail regulate CD80 redistribution and T cell costimulation. J Immunol (1998) 161:2700-7.

96. Sanchez-Lockhart M, Graf B, Miller J. Signals and sequences that control $\mathrm{CD} 28$ localization to the central region of the immunological synapse. J Immunol (2008) 181:7639-48. doi:10.4049/jimmunol.181.11.7639

97. Egen JG, Allison JP. Cytotoxic T lymphocyte antigen-4 accumulation in the immunological synapse is regulated by TCR signal strength. Immunity (2002) 16:23-35. doi:10.1016/S1074-7613(01)00259-X

98. Cefai D, Schneider H, Matangkasombut O, Kang H, Brody J, Rudd CE. CD28 receptor endocytosis is targeted by mutations that disrupt phosphatidylinositol 3-kinase binding and costimulation. J Immunol (1998) 160:2223-30.

99. Wulfing C, Davis MM. A receptor/cytoskeletal movement triggered by costimulation during $\mathrm{T}$ cell activation. Science (1998) 282:2266-9. doi:10.1126/science.282.5397.2266

100. Tskvitaria-Fuller I, Rozelle AL, Yin HL, Wulfing C. Regulation of sustained actin dynamics by the TCR and costimulation as a mechanism of receptor localization. J Immunol (2003) 171:2287-95. doi:10.4049/ jimmunol.171.5.2287

101. Kaga S, Ragg S, Rogers KA, Ochi A. Stimulation of CD28 with B7-2 promotes focal adhesion-like cell contacts where Rho family small $\mathrm{G}$ proteins accumulate in T cells. J Immunol (1998) 160:24-7.

102. Nunes JA, Collette Y, Truneh A, Olive D, Cantrell DA. The role of p21ras in $\mathrm{CD} 28$ signal transduction: triggering of $\mathrm{CD} 28$ with antibodies, but not the ligand B7-1, activates p21ras. J Exp Med (1994) 180:1067-76. doi:10.1084/ jem.180.3.1067

103. Salazar-Fontana LI, Barr V, Samelson LE, Bierer BE. CD28 engagement promotes actin polymerization through the activation of the small Rho GTPase Cdc42 in human T cells. JImmunol (2003) 171:2225-32. doi:10.4049/ jimmunol.171.5.2225

104. Raab M, Pfister S, Rudd CE. CD28 signaling via VAV/SLP-76 adaptors: regulation of cytokine transcription independent of TCR ligation. Immunity (2001) 15:921-33. doi:10.1016/S1074-7613(01)00248-5

105. Kim HH, Tharayil M, Rudd CE. Growth factor receptor-bound protein 2 $\mathrm{SH} 2 / \mathrm{SH} 3$ domain binding to CD28 and its role in co-signaling. J Biol Chem (1998) 273:296-301. doi:10.1074/jbc.273.1.296

106. Schneider H, Rudd CE. CD28 and Grb-2, relative to Gads or Grap, preferentially co-operate with Vav1 in the activation of NFAT/AP-1 transcription. Biochem Biophys Res Commun (2008) 369:616-21. doi:10.1016/j. bbrc.2008.02.068

107. Muscolini M, Camperio C, Porciello N, Caristi S, Capuano C, Viola A, et al. Phosphatidylinositol 4-phosphate 5-kinase alpha and Vav1 mutual cooperation in CD28-mediated actin remodeling and signaling functions. J Immunol (2015) 194:1323-33. doi:10.4049/jimmunol.1401643 
108. Tavano R, Contento RL, Baranda SJ, Soligo M, Tuosto L, Manes S, et al. CD28 interaction with filamin-A controls lipid raft accumulation at the T-cell immunological synapse. Nat Cell Biol (2006) 8:1270-6. doi:10.1038/ncb1492

109. Razinia Z, Makela T, Ylanne J, Calderwood DA. Filamins in mechanosensing and signaling. Annu Rev Biophys (2012) 41:227-46. doi:10.1146/ annurev-biophys-050511-102252

110. Tian R, Wang H, Gish GD, Petsalaki E, Pasculescu A, Shi Y, et al. Combinatorial proteomic analysis of intercellular signaling applied to the CD28 T-cell costimulatory receptor. Proc Natl Acad Sci U S A (2015) 112:E1594-603. doi:10.1073/pnas.1503286112

111. Muscolini M, Sajeva A, Caristi S, Tuosto L. A novel association between filamin A and NF-kappaB inducing kinase couples CD28 to inhibitor of NF-kappaB kinase alpha and NF-kappaB activation. Immunol Lett (2011) 136:203-12. doi:10.1016/j.imlet.2011.01.011

112. Edwards M, Zwolak A, Schafer DA, Sept D, Dominguez R, Cooper JA. Capping protein regulators fine-tune actin assembly dynamics. Nat Rev Mole Cell Biol (2014) 15:677-89. doi:10.1038/nrm3869

113. Liang Y, Cucchetti M, Roncagalli R, Yokosuka T, Malzac A, Bertosio E, et al. The lymphoid lineage-specific actin-uncapping protein Rltpr is essential for costimulation via CD28 and the development of regulatory T cells. Nat Immunol (2013) 14:858-66. doi:10.1038/ni.2634

114. Samstag Y, John I, Wabnitz GH. Cofilin: a redox sensitive mediator of actin dynamics during T-cell activation and migration. Immunol Rev (2013) 256:30-47. doi:10.1111/imr.12115

115. Agnew BJ, Minamide LS, Bamburg JR. Reactivation of phosphorylated actin depolymerizing factor and identification of the regulatory site. J Biol Chem (1995) 270:17582-7. doi:10.1074/jbc.270.29.17582

116. Moriyama K, Iida K, Yahara I. Phosphorylation of Ser-3 of cofilin regulates its essential function on actin. Genes Cells (1996) 1:73-86. doi:10.1046/j.1365-2443.1996.05005.x

117. Yonezawa N, Homma Y, Yahara I, Sakai H, Nishida E. A short sequence responsible for both phosphoinositide binding and actin binding activities of cofilin. J Biol Chem (1991) 266:17218-21.

118. Eibert SM, Lee KH, Pipkorn R, Sester U, Wabnitz GH, Giese T, et al. Cofilin peptide homologs interfere with immunological synapse formation and $\mathrm{T}$ cell activation. Proc Natl Acad Sci U S A (2004) 101:1957-62. doi:10.1073/ pnas. 0308282100

119. Lee KH, Meuer SC, Samstag Y.Cofilin: a missinglinkbetween T cell co-stimulation and rearrangement of theactincytoskeleton.EurJ Immunol(2000)30:8929. doi:10.1002/1521-4141(200003)30:3<892::AID-IMMU892>3.3.CO;2-L

120. Wabnitz GH, Nebl G, Klemke M, Schroder AJ, Samstag Y. Phosphatidylinositol 3-kinase functions as a Ras effector in the signaling cascade that regulates dephosphorylation of the actin-remodeling protein cofilin after costimulation of untransformed human T lymphocytes. J Immunol (2006) 176:1668-74. doi:10.4049/jimmunol.176.3.1668

121. Ambach A, Saunus J, Konstandin M, Wesselborg S, Meuer SC, Samstag Y. The serine phosphatases PP1 and PP2A associate with and activate the actin-binding protein cofilin in human Tlymphocytes. Eur Immunol (2000) 30:3422-31. doi:10.1002/1521-4141(2000012)30:12<3422::AID-IMMU3422>3.0.CO;2-J

122. Dilek N, Poirier N, Hulin P, Coulon F, Mary C, Ville S, et al. Targeting CD28, CTLA-4 and PD-L1 costimulation differentially controls immune synapses and function of human regulatory and conventional T-cells. PLoS One (2013) 8:e83139. doi:10.1371/journal.pone.0083139

123. Michel F, Attal-Bonnefoy G, Mangino G, Mise-Omata S, Acuto O. CD28 as a molecular amplifier extending TCR ligation and signaling capabilities. Immunity (2001) 15:935-45. doi:10.1016/S1074-7613(01)00244-8

124. Kong KF, Yokosuka T, Canonigo-Balancio AJ, Isakov N, Saito T, Altman A. A motif in the V3 domain of the kinase PKC-theta determines its localization in the immunological synapse and functions in $\mathrm{T}$ cells via association with CD28. Nat Immunol (2011) 12:1105-12. doi:10.1038/ni.2120

125. Tan YX, Manz BN, Freedman TS, Zhang C, Shokat KM, Weiss A. Inhibition of the kinase Csk in thymocytes reveals a requirement for actin remodeling in the initiation of full TCR signaling. Nat Immunol (2014) 15:186-94. doi:10.1038/ni.2772

126. Pfeifhofer-Obermair C, Thuille N, Baier G. Involvement of distinct PKC gene products in T cell functions. Front Immunol (2012) 3:220. doi:10.3389/ fimmu.2012.00220
127. Monks CR, Kupfer H, Tamir I, Barlow A, Kupfer A. Selective modulation of protein kinase C-theta during T-cell activation. Nature (1997) 385:83-6. doi: $10.1038 / 385083 \mathrm{a} 0$

128. Fu G, Hu J, Niederberger-Magnenat N, Rybakin V, Casas J, Yachi PP, et al. Protein kinase $\mathrm{C}$ eta is required for $\mathrm{T}$ cell activation and homeostatic proliferation. Sci Signal (2011) 4:ra84. doi:10.1126/scisignal.2002058

129. Quann EJ, Liu X, Altan-Bonnet G, Huse M. A cascade of protein kinase C isozymes promotes cytoskeletal polarization in T cells. Nat Immunol (2011) 12:647-54. doi:10.1038/ni.2033

130. Singleton KL, Roybal KT, Sun Y, Fu G, Gascoigne NR, van Oers NS, et al. Spatiotemporal patterning during T cell activation is highly diverse. Sci Signal (2009) 2:ra15. doi:10.1126/scisignal.2000199

131. Fu G, Gascoigne NR. The role of protein kinase ceta in T cell biology. Front Immunol (2012) 3:177. doi:10.3389/fimmu.2012.00177

132. Kong KF, Altman A. In and out of the bull's eye: protein kinase Cs in the immunological synapse. Trends Immunol (2013) 34:234-42. doi:10.1016/j. it.2013.01.002

133. Huang J, Lo PF, Zal T, Gascoigne NR, Smith BA, Levin SD, et al. CD28 plays a critical role in the segregation of PKC theta within the immunologic synapse. Proc Natl Acad Sci U S A (2002) 99:9369-73. doi:10.1073/pnas.142298399

134. Basu R, Chen Y, Quann EJ, Huse M. The variable hinge region of novel PKCs determines localization to distinct regions of the immunological synapse. PLoS One (2014) 9:e95531. doi:10.1371/journal.pone.0095531

135. Quann EJ, Merino E, Furuta T, Huse M. Localized diacylglycerol drives the polarization of the microtubule-organizing center in T cells. Nat Immunol (2009) 10:627-35. doi:10.1038/ni.1734

136. Carrasco S, Merida I. Diacylglycerol-dependent binding recruits PKCtheta and RasGRP1 C1 domains to specific subcellular localizations in living T lymphocytes. Mol Biol Cell (2004) 15:2932-42. doi:10.1091/mbc.E03-11-0844

137. Thuille N, Heit I, Fresser F, Krumbock N, Bauer B, Leuthaeusser S, et al. Critical role of novel Thr-219 autophosphorylation for the cellular function of PKCtheta in T lymphocytes. EMBO J (2005) 24:3869-80. doi:10.1038/ sj.emboj.7600856

138. Cartwright NG, Kashyap AK, Schaefer BC. An active kinase domain is required for retention of PKCtheta at the T cell immunological synapse. $\mathrm{Mol}$ Biol Cell (2011) 22:3491-7. doi:10.1091/mbc.E10-11-0916

139. Wang XD, Gong Y, Chen ZL, Gong BN, Xie JJ, Zhong CQ, et al. TCR-induced sumoylation of the kinase PKC-theta controls $\mathrm{T}$ cell synapse organization and T cell activation. Nat Immunol (2015) 16:1195-203. doi:10.1038/ni.3259

140. Takahashi T, Tagami T, Yamazaki S, Uede T, Shimizu J, Sakaguchi N, et al. Immunologic self-tolerance maintained by CD25(+)CD4(+) regulatory $\mathrm{T}$ cells constitutively expressing cytotoxic T lymphocyte-associated antigen 4 . J Exp Med (2000) 192:303-10. doi:10.1084/jem.192.2.303

141. Yokosuka T, Kobayashi W, Takamatsu M, Sakata-Sogawa K, Zeng H, Hashimoto-Tane A, et al. Spatiotemporal basis of CTLA-4 costimulatory molecule-mediated negative regulation of T cell activation. Immunity (2010) 33:326-39. doi:10.1016/j.immuni.2010.09.006

142. Linsley PS, Bradshaw J, Greene J, Peach R, Bennett KL, Mittler RS. Intracellular trafficking of CTLA-4 and focal localization towards sites of TCR engagement. Immunity (1996) 4:535-43. doi:10.1016/S1074-7613(00)80480-X

143. Schneider H, Smith X, Liu H, Bismuth G, Rudd CE. CTLA-4 disrupts ZAP70 microcluster formation with reduced $\mathrm{T}$ cell/APC dwell times and calcium mobilization. Eur J Immunol (2008) 38:40-7. doi:10.1002/eji.200737423

144. Brzostek J, Chai JG, Gebhardt F, Busch DH, Zhao R, van der Merwe PA, et al. Ligand dimensions are important in controlling NK-cell responses. Eur J Immunol (2010) 40:2050-9. doi:10.1002/eji.201040335

145. Kohler K, Xiong S, Brzostek J, Mehrabi M, Eissmann P, Harrison A, et al. Matched sizes of activating and inhibitory receptor/ligand pairs are required for optimal signal integration by human natural killer cells. PLoS One (2010) 5:e15374. doi:10.1371/journal.pone.0015374

146. Qureshi OS, Zheng Y, Nakamura K, Attridge K, Manzotti C, Schmidt EM, et al. Trans-endocytosis of CD80 and CD86: a molecular basis for the cell-extrinsic function of CTLA-4. Science (2011) 332:600-3. doi:10.1126/ science. 1202947

147. Tadokoro CE, Shakhar G, Shen S, Ding Y, Lino AC, Maraver A, et al. Regulatory $\mathrm{T}$ cells inhibit stable contacts between CD4+ T cells and dendritic cells in vivo. J Exp Med (2006) 203:505-11. doi:10.1084/jem.20050783 
148. Tang Q, Adams JY, Tooley AJ, Bi M, Fife BT, Serra P, et al. Visualizing regulatory $\mathrm{T}$ cell control of autoimmune responses in nonobese diabetic mice. Nat Immunol (2006) 7:83-92. doi:10.1038/ni1289

149. Sumoza-Toledo A, Eaton AD, Sarukhan A. Regulatory T cells inhibit protein kinase $\mathrm{C}$ theta recruitment to the immune synapse of naive $\mathrm{T}$ cells with the same antigen specificity. J Immunol (2006) 176:5779-87. doi:10.4049/ jimmunol.176.10.5779

150. Kastenmuller W, Gasteiger G, Subramanian N, Sparwasser T, Busch DH, Belkaid Y, et al. Regulatory T cells selectively control CD8+ T cell effector pool size via IL-2 restriction. J Immunol (2011) 187:3186-97. doi:10.4049/ jimmunol.1101649

151. Zanin-Zhorov A, Ding Y, Kumari S, Attur M, Hippen KL, Brown M, et al. Protein kinase C-theta mediates negative feedback on regulatory $\mathrm{T}$ cell function. Science (2010) 328:372-6. doi:10.1126/science.1186068

152. Kong KF, Fu G, Zhang Y, Yokosuka T, Casas J, Canonigo-Balancio AJ, et al. Protein kinase C-eta controls CTLA-4-mediated regulatory T cell function. Nat Immunol (2014) 15:465-72. doi:10.1038/ni.2866

153. Borriello F, Sethna MP, Boyd SD, Schweitzer AN, Tivol EA, Jacoby D, et al. B7-1 and B7-2 have overlapping, critical roles in immunoglobulin class switching and germinal center formation. Immunity (1997) 6:303-13. doi:10.1016/S1074-7613(00)80333-7

154. Lanier LL, O’Fallon S, Somoza C, Phillips JH, Linsley PS, Okumura K, et al. CD80 (B7) and CD86 (B70) provide similar costimulatory signals for T cell proliferation, cytokine production, and generation of CTL. J Immunol (1995) 154:97-105.

155. Zheng Y, Manzotti CN, Liu M, Burke F, Mead KI, Sansom DM. CD86 and CD80 differentially modulate the suppressive function of human regulatory T cells. J Immunol (2004) 172:2778-84. doi:10.4049/jimmunol.172.5.2778

156. Schneider H, Downey J, Smith A, Zinselmeyer BH, Rush C, Brewer JM, et al. Reversal of the TCR stop signal by CTLA-4. Science (2006) 313:1972-5. doi:10.1126/science.1131078

157. Miska J, Abdulreda MH, Devarajan P, Lui JB, Suzuki J, Pileggi A, et al. Realtime immune cell interactions in target tissue during autoimmune-induced damage and graft tolerance. J Exp Med (2014) 211:441-56. doi:10.1084/ jem.20130785

158. Pentcheva-Hoang T, Simpson TR, Montalvo-Ortiz W, Allison JP. Cytotoxic T lymphocyte antigen- 4 blockade enhances antitumor immunity by stimulating melanoma-specific T-cell motility. Cancer Immunol Res (2014) 2:970-80. doi:10.1158/2326-6066.CIR-14-0104

159. Ruocco MG, Pilones KA, Kawashima N, Cammer M, Huang J, Babb JS, et al. Suppressing T cell motility induced by anti-CTLA-4 monotherapy improves antitumor effects. J Clin Invest (2012) 122:3718-30. doi:10.1172/JCI61931

160. Lu Y, Schneider H, Rudd CE. Murine regulatory T cells differ from conventional T cells in resisting the CTLA-4 reversal of TCR stop-signal. Blood (2012) 120:4560-70. doi:10.1182/blood-2012-04-421420

161. Onishi Y, Fehervari Z, Yamaguchi T, Sakaguchi S. Foxp3+ natural regulatory $\mathrm{T}$ cells preferentially form aggregates on dendritic cells in vitro and actively inhibit their maturation. Proc Natl Acad Sci U S A (2008) 105:10113-8. doi:10.1073/pnas.0711106105

162. Oderup C, Cederbom L, Makowska A, Cilio CM, Ivars F. Cytotoxic T lymphocyte antigen-4-dependent down-modulation of costimulatory molecules on dendritic cells in CD4+ CD25+ regulatory T-cell-mediated suppression. Immunology (2006) 118:240-9. doi:10.1111/j.1365-2567.2006.02362.x

163. Thauland TJ, Koguchi Y, Dustin ML, Parker DC. CD28-CD80 interactions control regulatory $\mathrm{T}$ cell motility and immunological synapse formation. J Immunol (2014) 193:5894-903. doi:10.4049/jimmunol.1401752

164. Fife BT, Pauken KE, Eagar TN, Obu T, Wu J, Tang Q, et al. Interactions between PD-1 and PD-L1 promote tolerance by blocking the TCR-induced stop signal. Nat Immunol (2009) 10:1185-92. doi:10.1038/ni.1790

165. Stritesky GL, Jameson SC, Hogquist KA. Selection of self-reactive T cells in the thymus. Annu Rev Immunol (2012) 30:95-114. doi:10.1146/ annurev-immunol-020711-075035
166. Hara S, Nakaseko C, Yamasaki S, Hattori M, Bos JL, Saito Y, et al. Involvement of Rap-1 activation and early termination of immune synapse in CTLA-4mediated negative signal. Hematology (2009) 14:150-8. doi:10.1179/10245 3309X402241

167. Dillon TJ, Carey KD, Wetzel SA, Parker DC, Stork PJ. Regulation of the small GTPase Rap1 and extracellular signal-regulated kinases by the costimulatory molecule CTLA-4. Mol Cell Biol (2005) 25:4117-28. doi:10.1128/ MCB.25.10.4117-4128.2005

168. Kloog Y, Mor A. Cytotoxic-T-lymphocyte antigen 4 receptor signaling for lymphocyte adhesion is mediated by C3G and Rap1. Mol Cell Biol (2014) 34:978-88. doi:10.1128/MCB.01024-13

169. Schneider H, Valk E, da Rocha Dias S, Wei B, Rudd CE. CTLA-4 up-regulation of lymphocyte function-associated antigen 1 adhesion and clustering as an alternate basis for coreceptor function. Proc Natl Acad Sci U S A (2005) 102:12861-6. doi:10.1073/pnas.0505802102

170. Catalfamo M, Tai X, Karpova T, McNally J, Henkart PA. TcRinduced regulated secretion leads to surface expression of CTLA-4 in CD4+CD25+ T cells. Immunology (2008) 125:70-9. doi:10.1111/j.1365-2567.2008.02822.x

171. Hailman E, Burack WR, Shaw AS, Dustin ML, Allen PM. Immature CD4(+) CD8(+) thymocytes form a multifocal immunological synapse with sustained tyrosine phosphorylation. Immunity (2002) 16:839-48. doi:10.1016/ S1074-7613(02)00326-6

172. Richie LI, Ebert PJ, Wu LC, Krummel MF, Owen JJ, Davis MM. Imaging synapse formation during thymocyte selection: inability of CD3zeta to form a stable central accumulation during negative selection. Immunity (2002) 16:595-606. doi:10.1016/S1074-7613(02)00299-6

173. Sun Z, Arendt CW, Ellmeier W, Schaeffer EM, Sunshine MJ, Gandhi $\mathrm{L}$, et al. PKC-theta is required for TCR-induced NF-kappaB activation in mature but not immature T lymphocytes. Nature (2000) 404:402-7. doi: $10.1038 / 35006090$

174. Zambricki E, Zal T, Yachi P, Shigeoka A, Sprent J, Gascoigne N, et al. In vivo anergized $\mathrm{T}$ cells form altered immunological synapses in vitro. Am J Transplant (2006) 6:2572-9. doi:10.1111/j.1600-6143.2006.01517.x

175. Filipenko NR, Attwell S, Roskelley C, Dedhar S. Integrin-linked kinase activity regulates Rac- and Cdc42-mediated actin cytoskeleton reorganization via alpha-PIX. Oncogene (2005) 24:5837-49. doi:10.1038/ sj.onc. 1208737

176. Apostolou I, Sarukhan A, Klein L, von Boehmer H. Origin of regulatory T cells with known specificity for antigen. Nat Immunol (2002) 3:756-63. doi:10.1038/ni816

177. Knoechel B, Lohr J, Kahn E, Bluestone JA, Abbas AK. Sequential development of interleukin 2-dependent effector and regulatory T cells in response to endogenous systemic antigen. J Exp Med (2005) 202:1375-86. doi:10.1084/ jem. 20050855

178. Walker LS, Chodos A, Eggena M, Dooms H, Abbas AK. Antigen-dependent proliferation of CD4+ CD25+ regulatory T cells in vivo. J Exp Med (2003) 198:249-58. doi:10.1084/jem.20030315

179. Schmidt AM, Lu W, Sindhava VJ, Huang Y, Burkhardt JK, Yang E, et al. Regulatory T cells require TCR signaling for their suppressive function. J Immunol (2015) 194:4362-70. doi:10.4049/jimmunol.1402384

Conflict of Interest Statement: The authors declare that the research was conducted in the absence of any commercial or financial relationships that could be construed as a potential conflict of interest.

Copyright $\odot 2016$ Brzostek, Gascoigne and Rybakin. This is an open-access article distributed under the terms of the Creative Commons Attribution License (CC BY). The use, distribution or reproduction in other forums is permitted, provided the original author(s) or licensor are credited and that the original publication in this journal is cited, in accordance with accepted academic practice. No use, distribution or reproduction is permitted which does not comply with these terms. 